\title{
Evaluation of the expansion of behavioral health services in a rural, primary care clinic: A pilot project
}

\author{
Carolyn L. Donovan \\ West Virginia University
}

Follow this and additional works at: https://researchrepository.wvu.edu/etd

\section{Recommended Citation}

Donovan, Carolyn L., "Evaluation of the expansion of behavioral health services in a rural, primary care clinic: A pilot project" (2009). Graduate Theses, Dissertations, and Problem Reports. 3504.

https://researchrepository.wvu.edu/etd/3504

This Dissertation is protected by copyright and/or related rights. It has been brought to you by the The Research Repository @ WVU with permission from the rights-holder(s). You are free to use this Dissertation in any way that is permitted by the copyright and related rights legislation that applies to your use. For other uses you must obtain permission from the rights-holder(s) directly, unless additional rights are indicated by a Creative Commons license in the record and/ or on the work itself. This Dissertation has been accepted for inclusion in WVU Graduate Theses, Dissertations, and Problem Reports collection by an authorized administrator of The Research Repository @ WVU.

For more information, please contact researchrepository@mail.wvu.edu. 
Evaluation of the Expansion of Behavioral Health Services in a Rural, Primary Care Clinic: A Pilot Project

\author{
Carolyn L. Donovan, MSN, PMHCNS - BC, FNP-C \\ Doctoral Research Project submitted to the \\ School of Nursing \\ at West Virginia University \\ in partial fulfillment of the requirements for the degree of \\ Doctor of Nursing Practice
}

Susan McCrone, PhD, RN Chair

Aaron Henry, MBA

Nan Leslie, PhD, RN

Benjamin Miller, PsyD.

Morgantown, WV

2009

Keywords: integration, collaboration, behavioral health, primary care, colocation, barriers 


\begin{abstract}
Evaluation of the Expansion of Behavioral Health Services in a Rural, Primary Care Clinic: A Pilot Project
\end{abstract}

\title{
Carolyn L. Donovan
}

The trend towards integrated behavioral health and primary care services has been supported by the literature. To meet the growing demand for such services, one rural primary care clinic initiated and evaluated a pilot program increasing the number of behavioral health providers. One additional counselor was hired for six hours a week for twelve weeks. The aim of the evaluation was to determine if there was an increase in availability of services, improved communication about referred patients among providers, and increased satisfaction among patients. While outcomes were not statistically significant, positive changes were noted in all areas. The implementation was hampered by budgetary constraints, hiring freezes and space limitations. The evaluation of the pilot supports expansion of integrated services in the clinic. 


\section{Acknowledgements}

I would like to extend my sincerest appreciation to my capstone committee, Dr. Susan McCrone, Aaron Henry, Dr. Nan Leslie, and Dr. Ben Miller, whose guidance, wisdom and support made this project possible.

A special note of thanks is conveyed to those mentors in the field of psychology and nursing who encouraged my growth through the years - the late Dr. Donald Carter, Dr, John Zuboy and Dr. Mary Jane Smith; all very special teachers.

To my husband, Fred, special thanks for his patience, understanding and support that shone the light at the darkest hours and lastly, I dedicate this work to my mother, Dorothy O’Donnell, RN, who influenced my career choice and whose presence is sorely missed at the completion of this project. 
Table of Contents

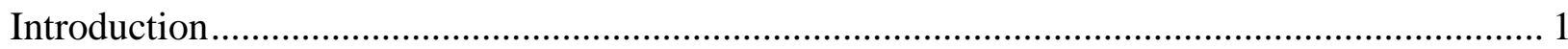

Significance of the Problem.............................................................................. 1

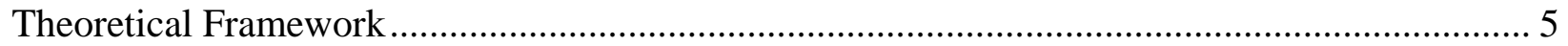

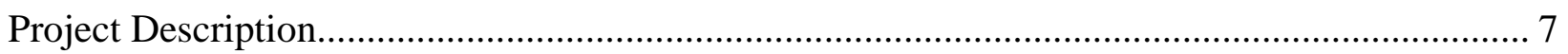

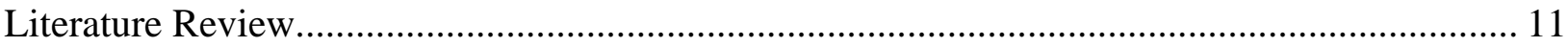

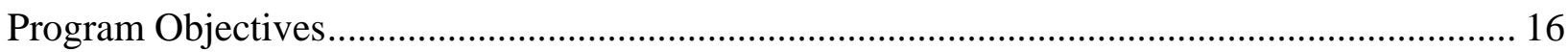

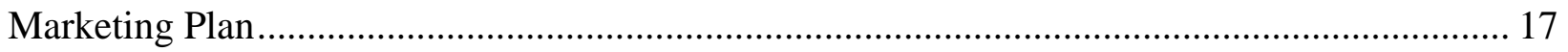

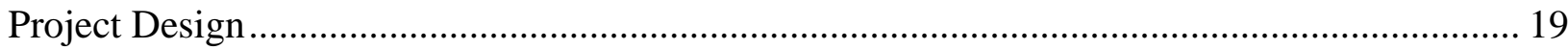

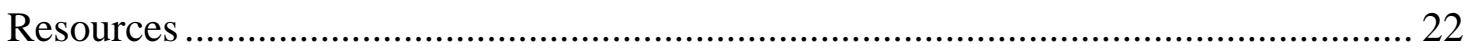

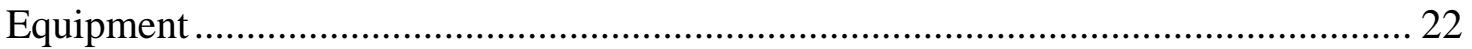

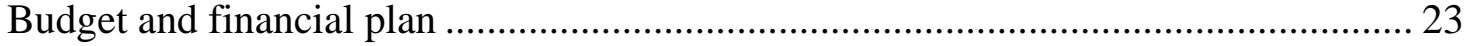

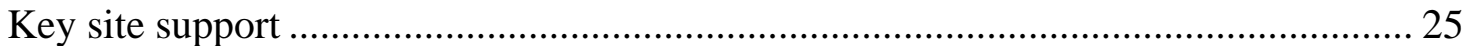

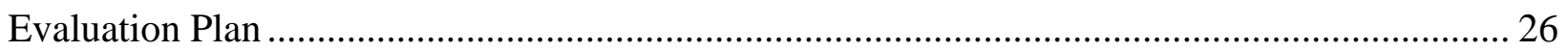

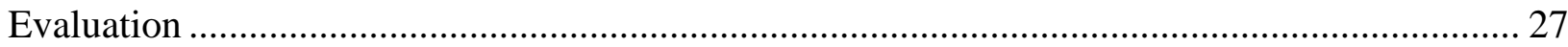

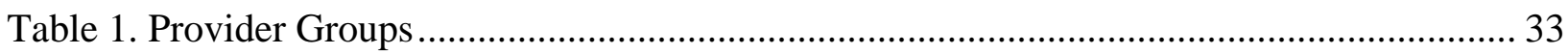

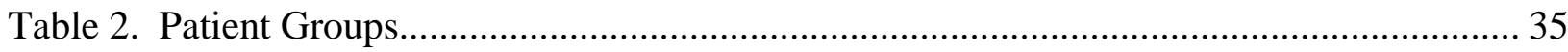

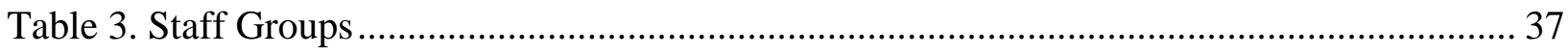

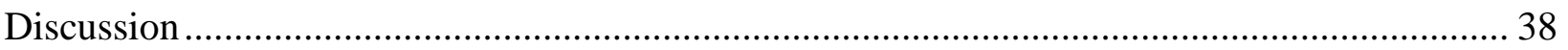

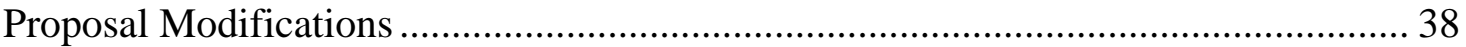

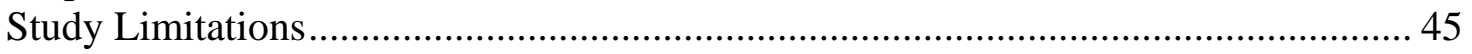

Application of Theoretical Framework....................................................................... 46

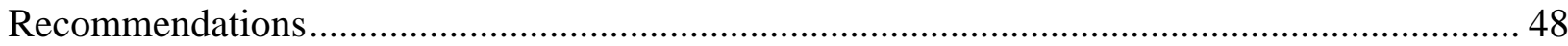

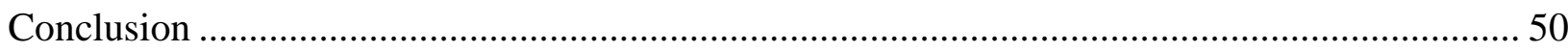

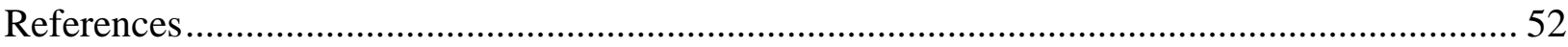


Appendix A: Certificate Program in Primary Care Behavioral Health .................................... 61

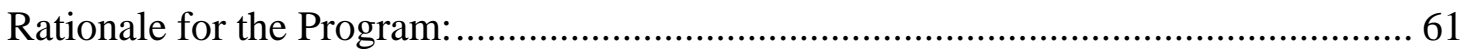

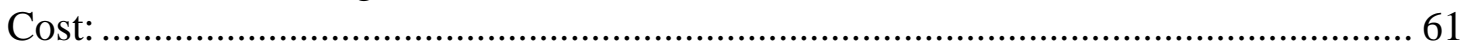

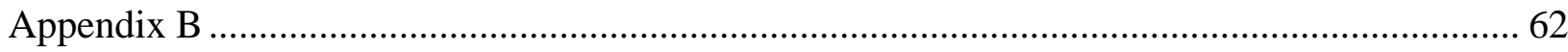

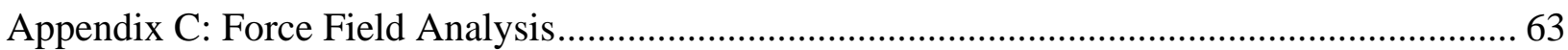

Appendix D: Proforma Budget for Behavioral Health Clinicians ........................................ 64

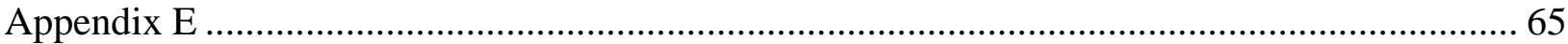

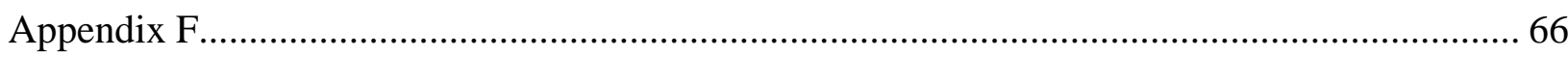

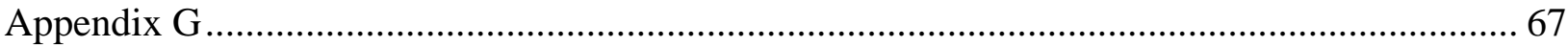

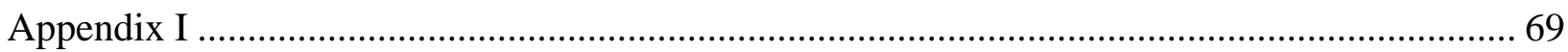

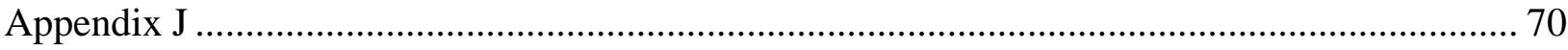

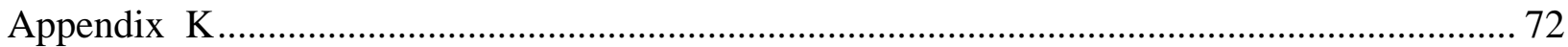

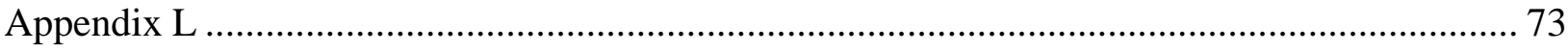

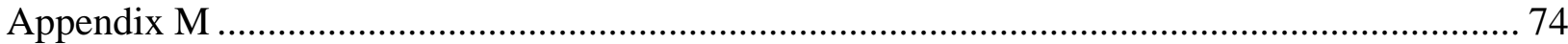

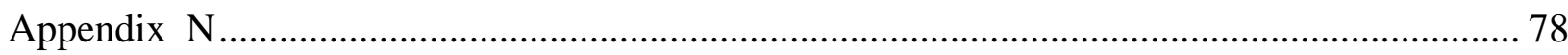

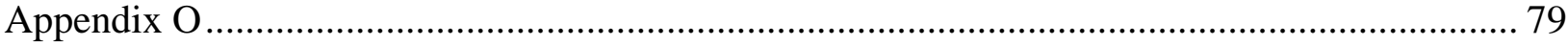

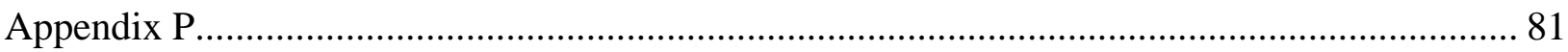

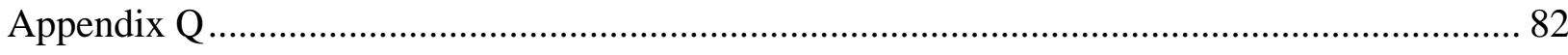

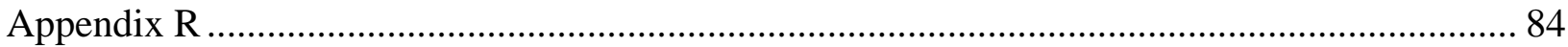

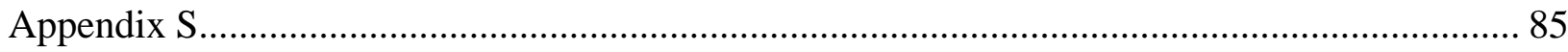


Introduction

Significance of the Problem

The topic of mental health problems in primary care has been well documented in the literature (Regier et al., 1993; deGruy, 1996; Blount, 1998; Strosahl, 1998; Bower \& Sibbald, 2003; Tovian, 2009). In 1993, Reiger et al. identified primary care as the defacto mental health system in the United States. The authors identified that most people with mental health concerns sought services in the primary care setting. Estimates vary, but it has been identified that approximately $50 \%$ of all mental health services are provided in primary care (DHHR, 1999; AAFP, 2001; Henning, 2000; WHO, 2001; Lui et al., 2003; Kessler, 2009). One study found that $60 \%$ to $70 \%$ of patients presenting symptoms to their primary care provider have no diagnosable somatic disorder (Reiger et al., 1993). These are symptoms that have no biological basis and account for physical complaints such as chest pain, shortness of breath, fatigue, dizziness, insomnia, abdominal pain and numbness. The mental health problems identified in this paper include not only disorders that are diagnosable according to the DSM-IV, but also subthreshold problems such as stress, relationship difficulties, and financial hardships (deGruy, 1996). The care of patients with complex medical problems as well as mental health problems is challenging to providers. Providing care for such patients can lead to overutilization of medical services, increased costs, and poorer patient outcomes (Lefevre et al., 1999; Horn, 2003; Cummings, O’Donohue, \& Cummings, 2009). 
Over the past ten years there has been a gradual shift from the biomedical approach of providing health care to a biopsychosocial approach (Engel, 1977). George Engel's seminal article on the biopsychosocial model in Science (1977) introduced a more comprehensive model of disease, which included biological, psychological and social factors. Further, as Engel outlined, instituting a new model of care would decrease the limitations of the biomedical model and offer a new approach to understanding and treating various diseases within health. The biopsychosocial model was proposed as an alternative to the traditional biomedical approach that had been pervasive throughout medical history.

A movement in patient care delivery that is informed by the biopsychosocial model is integrated care. Integrated care is defined as a model of integrating mental health clinicians into primary care (Blount, 2003; Miller, Mendenhall \& Malik, 2009). The terms integrated care and collaborative care have been used interchangeably throughout the literature, and will be used interchangeably in this manuscript as well. In 2002, the Report of the President's New Freedom Commission on Mental Health identified coordination between primary care and behavioral health as a major initiative (New Freedom Commission on Mental Health, 2002). Integrated mental and physical health care occurs when mental and general medical care providers work together to address both the physical and mental health needs of their patient (AHQR, 2008, p.9).

Although the biopsychosocial or integrated models of care appears to present a solution to service delivery, there are many barriers. Some barriers concerned the information or misinformation regarding mental health problems presented in primary care. These barriers implicated primary care providers, patients, and the system in which 
care was received as the predominate source of the problems (WHO, 2001). Providers, lacking sufficient skills and training, often misidentified symptoms (Goldman, Brody, \& Wise, 1998; Hodges, Inch, \& Silver, 2001). Patients may inappropriately represent their symptoms or withhold information fearing disclosure of their mental health issues, which leads to further misdiagnoses. The system is not always accepting of patients with mental health problems because social stigma identifies them as different, demanding, and frightening (deGruy, 1996). Unfortunately, inadequate recognition and treatment of mental health problems in primary care can lead to worsening comorbidities, chronicity of mental health problems, and at the extreme, possible suicide (Klinkman, 2003; Tylee \& Gandhi, 2005).

In 2000, the administration of Harpers Ferry Family Medicine, a rural health clinic, recognized the need for including behavioral health services in primary care. This was evident based upon the number of patients who were seen in the clinic with mental health related concerns. The trend toward integrated primary care behavioral health services was recognized and the service began in March, 2000. An advanced practice nurse (APRN) board certified in both adult mental health and family medicine was hired. An integrated or collaborative care model, in which a behavioral health provider was colocated in the clinic setting, or having shared office space and resources, was launched (Blount, 2003). Patients who would receive care were non-targeted with no psychiatric specific treatment modality identified. A non-targeted patient population refers to those patients who are diagnosed with a variety of mental health problems and are treated without a particular behavioral treatment strategy planned. For instance, a patient with anxiety may be taught relaxation exercises or hypnosis. However, this therapy plan would 
not predetermined. The targeted patient population differs in that a patient with a specific problem such as anxiety would be admitted to a predesigned group teaching diaphragmatic breathing. Each intervention for behavioral health service was established based on patient history, clinical assessment, and self administered psychiatric inventories such as the Mood Disorder Questionnaire (Hirschfield, 2002) and/or the Patient Health Questionnaire- 9 (PHQ-9; Spitzer, Kroenke, \& Williams, 1999). The interventions were conducted in a traditional mental health model allocating 30 or 45 minutes for each visit.

The integrated primary care behavioral health service has been successful since the inception. Visits have increased and have capped at 1500 adult patients seen yearly. The number of visits has doubled since 2001. However, with only one qualified behavioral health provider who has limited appointment times and a growing patient base, it has been deemed necessary to add additional providers to meet the needs of clinic patients. Patients are seen in a traditional mental health model which includes thirty or forty-five minute visits with the clinician. In addition, the service as an entity within the clinic lacks a formalized structure with policies.

One area of interest included in long term planning is certification for both mental health clinicians and for the formalized program. Clinician certification may be achieved through the Department of Family Medicine and Community Health of the University of Massachusetts Medical School. This certificate program will provide 36 hours of training specific to integration issues (Integrated Primary Care, 2009). The purpose of the program is to prepare mental health clinicians to work in primary care. Upon completion, the program provides a certificate to the learner. This program will be especially useful to 
new mental health graduates who were trained in a traditional behavioral health model (Appendix A).

Program accreditation would be sought from the Commission on Accreditation of Rehabilitation Facilities (CARF). CARF, under the Behavioral Health field categories, offers accreditation to a variety of mental health programs and facilities including integrated primary care /behavioral health programs (CARF, 2009). Accreditation has multiple benefits for a program. Accreditation assures that patients who seek care in an integrated primary care behavioral health program $(\mathrm{PCBH})$ will receive care that meets the high standards set by the accrediting body. In addition, quality standards dictated by CARF will be continuously monitored (Appendix B). Funds for certification for clinicians and the program will be considered based on future budgets and a financially sound program. As a long term goal, these certifications would elevate the status of the program by meeting the required standards and assisting clinicians in keeping current with treatment options.

Therefore, this project will address a plan to expand already existing integrated primary care behavioral health services in this clinic. The proposal will also discuss the program structure, recruitment, hiring and credentialing of clinicians.

\section{Theoretical Framework}

The conceptual framework guiding this project will be Kurt Lewin’s three step change theory. Lewin, a social scientist, believed an issue is held in balance by the interaction of two opposing sets of forces (Lewin, 1951). Forces seeking to change the system were labeled as driving forces, and those against the change, restraining forces. 
Lewin believed that organizations are systems in which the present situation is not a static pattern but a dynamic balance of forces working in opposition (Lewin, 1951). In order for change to occur, the driving force must exceed the restraining force. This component of Lewin’s theory is called force field analysis (Hershey, Blanchard, \& Johnson, 1996).

Three key concepts have been identified in Lewin's theories that make planned change occur: unfreezing the status quo, moving to a new state, and refreezing the change to make it permanent (Hershey, Blanchard, \& Johnson, 1996). In the unfreezing stage of this project, the problem identified is the lack of sufficient behavioral health services to meet the needs of the clinic population. The need for change will be communicated to the management of the clinic and also to various staff and providers. The APRN, in a continued effort to relay the need for change, will meet with the management to discuss the planned change. Information regarding increased demand for services, loss of referrals and revenue, and a plan for creative percentage fee for service pay for new hires will be presented and reviewed. This data will inform the change. Discomfort will arise from the unknown, particularly regarding the revenue generating potential of new hires and their ability to adjust their practice style to the primary care culture. Triage nurses will have concerns about the ability to schedule the new providers and billing staff will have concerns about credentialing and payments. These concerns have been discussed with regard to the current service by the staff when the service was initially started.

For planned change to successfully occur, it is important to unlock the status quo (Kassean \& Jagoo, 2005). Consistent with Lewin’s theory, a force field analysis will be completed (Appendix C). A timeline draft will be submitted to manage the change. This change process will be presented at a staff/ faculty meeting outlining the steps to be 
taken. The timeline is a six week period in which the unfreezing would occur. This would include: program development, space, fee for service structure, billing, and credentialing.

The moving phase will occur after advertising for the position results in the hiring of the clinicians. The new hires will begin to provide services as referrals will be appropriately directed to them. An evaluation of the services will occur at six weeks after

the inception of the expansion. Surveys will be given to patients regarding the availability of services and their satisfaction (Appendix H). Line and support staff will be encouraged to give feedback regarding the different aspects of the program. For instance, billing will provide feedback regarding pre-certification of insurances and collections since the hires will be multidisciplinary behavioral providers and not solely advanced practice psychiatric nurses. Also, feedback from faculty providers regarding the ease of referrals will be elicited.

In the refreezing phase of the capstone project, final change will be recognized at a staff /faculty meeting when the results of surveys and outcomes will be provided to the group. Additional feedback from the clinic administrator and program director will secure the new services. Staffing patterns for the clinicians would become permanent.

Lewin’s concepts are adaptable and relate well to this capstone project. The change model provides a process by which services can be expanded in a structured, planned approach with positive outcomes.

\section{Project Description}

This project proposal grew from the success of an existing service. The service has produced positive clinical outcomes for patients and providers. With an increase in 
demand for services and opportunities to increase services, the project will approach expansion as a planned change program. The program will have three specific objectives: (1) design and construct and integrated program; (2) hire additional behavioral health staff; and (3) secure certification for clinicians and the program. 


\begin{tabular}{|c|c|c|c|c|c|}
\hline Objective & Specifics & Measure & Action & Realistic & Timeline \\
\hline $\begin{array}{l}\text { 1. To } \\
\text { design and } \\
\text { construct } \\
\text { the } \\
\text { program }\end{array}$ & $\begin{array}{l}\text { Program } \\
\text { Structure }\end{array}$ & $\begin{array}{l}\text { Completed } \\
\text { policies } \\
\text { addressing no } \\
\text { shows, late } \\
\text { cancellation } \\
\text { policy, assessed } \\
\text { fees for n/s, } \\
\text { medication } \\
\text { refills, } \\
\text { continuity of } \\
\text { care }\end{array}$ & $\begin{array}{l}\text { Gathering and adapting policies from } \\
\text { other sources to provide guidelines to } \\
\text { IBH program; identifying paneling and } \\
\text { credentialing issues; site identified and } \\
\text { remodeling begun }\end{array}$ & Yes & November 22, 2008 \\
\hline $\begin{array}{l}\text { 2. To } \\
\text { interview } \\
\text { and hire } \\
\text { clinicians }\end{array}$ & $\begin{array}{l}\text { Hire } \\
\text { Clinicians }\end{array}$ & $\begin{array}{l}\text { One part time } \\
\text { clinician will be } \\
\text { hired }\end{array}$ & $\begin{array}{l}\text { Contract signed, background check } \\
\text { complete, office complete, paneling and } \\
\text { credentialing with insurance companies } \\
\text { completed, patients being referred to } \\
\text { provider; one chronic care group will } \\
\text { begin; } 2 \text { walk-in /emergency } \\
\text { appointments available per week; } 1 / 2 \text { day } \\
\text { clinic day for consultations }\end{array}$ & Yes & February 9, 2009 \\
\hline $\begin{array}{l}\text { 3. To } \\
\text { secure } \\
\text { certification }\end{array}$ & Certification & $\begin{array}{l}\text { Project manager } \\
\text { will be certified } \\
\text { as funds allow }\end{array}$ & $\begin{array}{l}\text { Completion of certification course } \\
\text { documented; } \\
\text { Application packet from CARF will be } \\
\text { requested as funds allow; voluntary } \\
\text { certification available to new } \\
\text { clinician(s) for } 2010 \text { program }\end{array}$ & Yes & January 2010 \\
\hline
\end{tabular}


The expansion project acknowledges the value of integrated primary care behavioral health services and recognizes that it is state of the art treatment for behavioral health problems (Blount, 1998; Strosahl, 1998; Robinson \& Reiter, 2007). The program is also congruent with the clinic’s newly adopted concept of “medical home”. The medical home concept gained attention from the "2002 Future of Family Medicine” project initiated by seven national family medicine organizations (Kahn, 2004). The patient centered care model or access model refers to a patient's ability to secure appropriate and preferred medical assistance where and when it is needed (Berry, Selders, \& Wilder, 2003). The guiding principles of the Patient Centered Medical Home (PCMH) are having a personal physician who directs the medical practice, providing a whole person orientation with integrated, coordinated care, quality and safety, technology and enhanced access to care (Graham, 2007). Integrated primary care behavioral health enriches and supports the medical home concept (Patterson, Phillips, Bazemore, Dodoo, Zhang, \& Green, 2008). Patients often comment on how smoothly a referral was made and what a convenience it is to receive mental health services within the primary care setting.

In keeping with the mission of Harpers Ferry Family Medicine and the Eastern Division of West Virginia University, the integrated behavioral health primary care program expansion will address the needs of patients, faculty, residents, medical students, and the community at large by providing high caliber care and excellent opportunities for learning. Expanding services will provide enhanced educational opportunities for family practice residents and other health sciences center students who may rotate through the clinic by incorporating the mental health care of patients within their primary care 
experiences. Teaching will occur through didactic education and real time interactions with patients in concert with the behavioral health professionals. In addition, at Harpers Ferry Family Medicine, there is a commitment to change in order to achieve excellence. New and innovative ways to serve patients are being explored within the context of the medical home concept. A Sunrise Sick Call Clinic, a webpage for patients, and email to providers from patients, are ways that patient satisfaction and the acceptance of the medical home have been promoted. Accessibility is a hallmark of the medical home and the ability for patients to see a behavioral health provider in their primary care facility is an important aspect of that care (Arvantes, 2008; Patterson et al., 2008).

\section{Literature Review}

The integration of primary care and behavioral or mental health care is a trend in patient care delivery that has grown over the last fifteen years. Integrated care is a model of delivery that emphasizes the connection of the mind and body and has been defined by several leaders in the field (Blount, 1998; Strosahl, 1998; Robinson \& Reiter, 2007). In the seminal work of George Engel (1977), medicine as it had been practiced was denounced. In addition, there was a declaration that this disconnected approach to care was inadequate to meet the complex needs of patients. This denunciation, and Engel's biopsychosocial model of care, paved the way for what we now identify as integrated primary care or integrated behavioral health care. Blount (1998) believes that by connecting physical and mental health care in a primary care setting, the body mind split is avoided. He further asserts that integrated primary care "is the structural realization of the biopsychosocial model that Engel advocated so broadly in family medicine” (p.2). 
Models of integrated and collaborative care between primary care and behavioral health have received numerous endorsements (AAFP, 1999; DHHR, 1999; WHO, 2001; SAMHSA, 2004).

While the field has grown and more information emerges, there are concerns about the continued preference for the biomedical model of care. Blount (1998) questions why "when the evidence appears to be so compelling, but has not been compelling enough” to change the paradigm completely (p.122). However, there is little high level evidence specifically demonstrating the efficacy of integrated care (AHRQ, 2008). Early literature discussed a collaborative care model while other authors described an integrated system. These terms have caused confusion in that each describes a different relationship within the medical and behavioral health systems (Blount, 2003). Doherty, McDaniel, \& Baird (1996) described dimensions of care between systems and define levels of collaboration. Further elucidation is provided by Blount (2003) who categorized the relationships between the providers, the relationships of service to populations, and specificity of services provided. In this paper, the terms "collaborative” and "integrated" have been used interchangeably.

Within existing research, response to integrated care has been positive but limited. In a randomized control trial (RCT) by Unutzer et al. (2002), a collaborative intervention program for late life depression was studied. This large study included eighteen primary care clinics in five states with six hundred fifty participants in both the control group and the intervention group. The outcome revealed decreased depression for the treatment group as well as increased quality of life. The authors do admit biases within the study which may have favorably affected the study. Notification to the referring physician 
when a patient meeting the study criteria was assigned to usual care was identified as a flaw. The authors surmise that this notification impacted treatment favorably in that the intervention may not have occurred in usual care (Unutzer, et al, 2002). Another limitation included reliance on self reports of medical conditions and on medication use.

Katon, Roy-Byrne, Russo, \& Crowley (2002) conducted a RCT in which one hundred fifteen primary care patients with panic disorder were assigned to a collaborative care intervention. This intervention included systematic patient education and two visits by a consulting psychiatrist. Telephone assessments were performed at three, six, nine, and twelve months. The results of the study indicated that the patients who received the intervention had more anxiety free days. The study further demonstrated lower costs with greater effectiveness. The authors note several limitations that may have affected the study. Failure to consider the effect of anxiety from a broader perspective such as employment (lost days and productivity) and on earning potential and marital stability was discussed (Katon et al., 2002). Additionally, patients’ time off from work to attend physician visits in the study, travel time to and from the clinic, waiting time in the clinic, and time with the physician were not considered. With adjusted calculations for both employed and unemployed patients, an additional cost savings per patient was associated with the collaborative care intervention.

An effectiveness study using survey data compared integrated mental health care with enhanced referral care. The study, “The Primary Care Research in Substance Abuse and Mental Health for the Elderly (PRISM-E)”, compared integrated behavioral health care versus enhanced referral care in primary care settings across the United States. Of the one hundred twenty seven clinicians who were surveyed, most preferred the 
integrated model for most of the mental health care (Gallo et al., 2004). Additionally, the respondents affirmed that communication between primary care clinicians and behavioral health clinicians was superior in collaborative care versus referral care. One limitation of this study was that the data was elicited via survey and may not be generalized to all clinicians. Another limitation was the small sample size.

Further support of an integrated model of care is described in a survey study by Farrar et al. (2001). This report described satisfaction surveys developed and sent to family physicians, psychiatrists, and counselors. Each questionnaire was specifically tailored to the respective discipline and each asked questions pertinent to patient and provider satisfaction. Results for all three groups indicated a high level of satisfaction with the integrated model. Generalization to other practice groups in this study was a limitation. Another limitation was that the survey data may sometimes be skewed in that respondents may wish to be seen in a positive way and may be reluctant to give negative answers.

A comprehensive review of more than sixty case studies was compiled by Blount (2003). In his review, the author reported that overall positive outcomes resulted from integrated care. The review portrays positive outcomes in: treatment effectiveness, satisfaction among patients, physicians, and behavioral health clinicians, and cost effectiveness. Blount (2003) states that the location and the service provided should be specified in order to adequately assess the outcomes. The distinction among coordinated, co-located, and integrated services assists in a clear understanding of the processes. Blount (2003) further clarifies the differences between targeted and non-targeted services to provide the reader with insight into the populations served. The author also defines 
treatment modalities that clarify intervention approaches used in integrated programs. The author reminds the reader that the information as a whole is confusing and the literature can be cumbersome.

A systematic analysis of the literature related to better practices in collaborative mental health care in primary care was conducted by Craven \& Bland (2006). The study revealed that there is a body of literature emerging on collaborative practice. Clinical implications included: collaboration is most successful when built on existing clinical relationships, enhanced collaboration should be paired with disorder-specific treatment guidelines, and skill transfer in collaborative relationships requires service restructuring in support of behavioral change (Craven \& Bland, 2006). The authors admit that because the numbers of studies are small and there is variation in the study methodologies, the analysis is limited.

This literature review discussed integrated primary care and the historical antecedents offered by George Engel. Existing research reviewed for this paper included two randomized controlled studies, two survey studies, a comprehensive literature review, and a systematic analysis. Although randomized control studies offer the highest level of evidence, both authors admitted flaws in the research that may have positively affected the outcome. The survey studies, which are considered less reliable, also supported the effectiveness of integrated care. The comprehensive review is also supportive of integrated care; details different aspects of care; and addresses location of services, populations served, and clinical effectiveness. The systematic analysis documents the emerging evidence for collaboration with positive clinical implications and supports higher levels of evidence. 
Focused research into the area of integrated care is warranted. With a better understanding of the relationships among providers and service to populations and specificity of services provided, this research will be made possible.

\section{Program Objectives}

The main program objective is the evaluation of the expansion of behavioral health services in a rural primary care clinic. The measurement of this expansion is the implementation of this program with written polices in place and clinicians hired. The total time for the program expansion is estimated to be four months based on the ability to hire part time contractual clinicians who are willing to work on a percentage of fees for service basis.

The first objective involves writing policies and procedures for the program. This task is estimated to take approximately six weeks. This will entail formulating and organizing the integrated primary care policies with already existing clinic polices. Included in this is the exploration of human resource information for the purpose of hiring a mental health clinician. This would also include: insurance paneling, credentialing, and development of contractual information to be presented to the new hires. Additionally, space would be identified and remodeling would begin to accommodate the new providers. The evaluation would include the completed policies and patient admission packet, a plan for contractual services, and finished work space.

The second objective is estimated to take six weeks. This would include:

advertising, interviewing, and hiring one or two clinicians for the positions at the site. Again, the time lag may be a result of identifying clinicians who would agree to work 
under a contractual work assignment. Once hired, the clinicians will be oriented and assigned to a schedule. The amount of time worked will be based on the demand for services. New services will be explored. For example, a chronic care group may be added to the schedule of brief intervention visits. Onsite consultations in the clinic with the residents will be available one half day per week. Evaluation of this phase would include: clinicians hired with signed contracts, completed orientation, and assignment of offices with full schedules. Onsite consultations will begin within the same time period and will reflect advancement towards diversifying services within the program.

The third and final objective, certification and credentialing, is a longer term goal. The certification process for the project manager has been discussed and some funds were allocated. However, budget reductions within the clinic system have compromised the ability to complete this objective as initially scheduled. Therefore, this objective will not be included in the evaluation process

\section{Marketing Plan}

The key stake holders in the project expansion are Dr. C. Mitch Jacques, Dean, West Virginia University, Eastern Division, Dr. K.C. Nau, Program Chair of Family Medicine, West Virginia University, Eastern Division and Aaron Henry, MBA, Administrator, Harpers Ferry Family Medicine, faculty providers, residents, support staff, and patients. A stake holder is a person or group having an interest in the success of an enterprise, business or movement (Morehead, 2006). Each stake holder has a different interest but is an important link in the process. For instance, Dr. Jacques, Dr. Nau and Mr. Henry are not only concerned with quality patient care, but also the financial feasibility, 
cost /benefit, and sustainability of the project. The faculty providers and residents are concerned with quality care but also with an expeditious referral process. The support staff members are interested in having more available appointments in which to schedule the patients, and the patients want quality, an expeditious service that is conveniently located within the primary care office setting.

A SWOT analysis is a facet of a marketing strategy and an essential part of strategic planning. A SWOT analysis is a process used in projects or business that can facilitate discussions on the strengths, weaknesses, opportunities and threats to the organizational processes (McClouskey \& Cusick, 2001). The SWOT analysis provides a roadmap to the organization. The SWOT analysis for this proposed project is described in the following paragraph.

Strengths are identified as internal attributes that are helpful in achieving the objectives (Hazelbaker \& Hall, 2006). In the proposed project, these include: administrative support, history of providing primary care behavioral health service, experienced project manager, and creative budgeting. Weaknesses in an organization are defined as those internal conditions that are harmful to achieving the objective of the organization (Hazelbaker \& Hall, 2006). Identified weaknesses in the system that could impact the proposed project are: the lack of acceptance of other mental health providers' services due to unfamiliarity with providers other than the Advanced Practice Nurse by the staff, credentialing and billing issues, improper scheduling, and inappropriate referrals. Opportunities are external conditions that are useful in achieving the objective of the organization (Hazelbaker \& Hall, 2006). Such opportunities include: increased demand for service, increasing patient population at Harpers Ferry Family Medicine and 
the recent trend toward the medical home model. Lastly, threats are external conditions that are harmful to achieving the objectives of the organization (Hazelbaker \& Hall, 2006). Threats considered in this proposal include: inability to hire clinicians due to part time status and billing/reimbursement issues, which would impact the financial feasibility of the program. Understanding these conditions will provide for better management of the project.

\section{Project Design}

This project is an evaluation of the impact of expansion of behavioral health services in a primary care setting. This project will involve a descriptive, longitudinal design to evaluate the expansion of services and stake holder satisfaction with the project. Surveys specifically designed to gather the information will be used. According to Polit \& Beck (2008), “a survey is designed to obtain information about the prevalence, distribution, and interrelations of variables with a population” (p.323). A survey is a systematic, standardized way to collect data. Surveys are uniform in that the same questions are posed to all respondents. In a survey, family physicians, psychiatrists and mental health counselors working in primary care were polled on their satisfaction with a collaborative care model vs. usual care. High levels of satisfaction were recorded with family physicians expressing increased comfort in handling mental health problems and were satisfied with the benefits to their patients (Farrar, Kates, Crustolo, \& Niklaoul, 2001).

The survey instruments that will be used are modeled after examples that have been offered in a toolkit for primary care behavioral health integration services and 
available for replication (Canadian Collaborative Mental Health Initiative, 2006). Not intended for research, validity and reliability have not been established for these instruments. Measurement on a Likert scale with $1=$ high and $7=$ low, will address issues of concern that present the most difficulty for faculty, providers, and staff. These concerns will include: accessibly, communication, and satisfaction.

To gather information about satisfaction with the expansion of services in this rural primary care clinic, written surveys will be distributed to the faculty and support staff in this project prior to the expansion and six weeks after the expansion to the faculty and support staff in this project. These surveys will be distributed to stake holders at the same point in time; thus gathering information from a cross section of stake holders (Melnyk \& Fineout-Overhold, 2005). Written surveys will be distributed to the faculty providers, who are primary care providers, during a faculty meeting (Appendix F). The surveys will be distributed by the program manager. Responses will remain anonymous and placed in a collection box in the program manager's office after the meeting. Surveys allow for quick responses and have minimal costs. The distribution of the surveys by the project manager will reinforce the importance of the surveys to the development of the new service.

Follow up surveys will be administered to patients after they have participated in the proposed service (Appendix H). Another written survey will be administered to the support and triage staff (Appendix G). It is their job to field calls from potential patients requesting appointments. In addition, the triage staff must deal with patients who request emergency visits when there are no mental health appointments available. Because of their direct communications with patients, these staff members are important stake 
holders. A way to best instruct the support and triage staff and obtain evaluation information from them would be to have a noon meeting and provide lunch. This would assure that respondents are educated on the survey and reinforce the program goals. These surveys would be administered within a one week window of the faculty surveys so that the process would be completed by November 29, 2008.

All data collected before program implementation will be discussed with the faculty and staff within the next month as the plans for the program unfolds. The approximate time line would be December 22, 2008. Questions will be answered at both the faculty meeting and a support staff meeting regarding the results and the proposed program. Timelines for phase one as previously described will be six weeks. Therefore, program construction and policy will be underway from November 22, 2008 until January 6, 2008.

The post implementation survey will be administered approximately six weeks after the inception of the expansion services being provided to patients. These surveys will be distributed to both faculty and support staff. Evaluative information will be shared with the survey participants in a timely manner using the previous meeting sites.

The goal of the survey is to evaluate the providers' needs for expanded services and measure their current satisfaction with the current service within the clinic. The survey will serve as a pretest within the project. These surveys will be distributed and collected at the November faculty meeting. 


\section{Resources}

Resources needed for this project are minimal. Policies and procedures will be gathered from integration resources and merged with existing University Health Associates polices. These policies will address clinic specific issues mentioned previously such as no show and late cancellations policies. All the resources needed for this phase of the project are in place and included in budget operations, such as binders, paper, and technical support.

Personnel requirements will involve meeting time with the administrator to discuss: contractual information, percentage of fees collected, patient no show rates, and late cancellations policies. These are issues that have challenged the program but have been overlooked. It is unacceptable to have these programmatic problems when clinicians are paid only for patients that they have seen. Brief meetings times will be also needed with billing staff, human resource, and clerical support staff. Because the service is already operational, these meetings dealing with the new program would require no extra time or cost because regular meetings with these personnel are routinely scheduled.

\section{Equipment}

Technology, space and furniture are items that must be purchased for the new clinicians. A computer and furniture for the newly hired clinician’s office has been estimated in the budget. Shared space will be available in the facility for additional clinicians as the clinic expansion is completed. Minimal renovation will be required for the space. 


\section{Budget and financial plan}

The gross revenue projected for the project is based on two staff clinicians. To ensure an adequate patient flow, clinician hours will be phased in over the course of twelve weeks. During the initial four weeks, one clinician will work one day or eight hours a week increasing in week five to sixteen hours per week. Beginning in week nine, a second clinician will be added for an additional eight hours of services for a total of twenty-hour hours per week. In week twelve and forward, the two clinicians will provide a total of thirty-two hours of service per week. The budget is based on the clinicians each working forty-eight weeks with the assumption that each clinician will take the equivalent of four weeks of vacation a year. Because patients will miss appointments for a variety of reasons and the staff will not be productive during these sessions, the revenue has been reduced by $12 \%$. This would include patient "no shows". Since most patients will have some third party insurance coverage, the gross revenue has been reduced to an estimated average insurance payment of $\$ 83$ per session based on current collectables. The resulting net patient revenue is the total operating revenue for the program since there will be no other sources of income.

The largest operating expense is the monies paid to the contract clinicians who will be providing the counseling services. Clinicians will be paid $60 \%$ of patient revenue for fees collected. Other significant expenses include a standard 10\% surcharge on collections for University Health Associates (UHA) support operations and the standard $10 \%$ surcharge on collections for Dean's Support. The Dean has waived the Dean's surcharge for the first six months to ease the cash flow deficit during this period. Other expenses include a 7\% charge on projected receivables to cover clerical costs and the 
estimated actual costs for rent and utilities. Five hundred dollars is budgeted for miscellaneous expenses and this line item provides some cushion for unexpected expenses. Built into the expense budget are the $0.6 \%$ West Virginia provider tax and an estimated bad debt expense of 5\%. Bad debt expense covers the loss of revenue when patient revenue is not collected such as when prior authorization for services is not obtained or co-pays are not collected. It should be noted that most of these expenses (clinician payments, UHA and Dean's surcharges, clerical costs, provider tax, and bad debt expense) vary with the operating revenue. Thus, if the program fails to meet its revenue targets, these expenses will proportionally decrease. In the same way, these expenses will increase if the program exceeds its revenue projections.

Start up expenses include additional furniture and a computer for the clinicians with an estimated total cost of $\$ 2000.00$. There is also staff recruitment expenses estimated at $\$ 500.00$. Included in this estimate are advertising fees for two local papers at approximately $\$ 250.00$. An additional cost of $\$ 150.00$ is estimated for lunch and travel during the recruitment process. Another $\$ 50.00$ is budgeted for supplies needed for recruitment such as folders, binders, and paper. Payment for staff orientation will be drawn from miscellaneous costs since the clinicians are paid on a fee for service basis. Therefore, it will be important to have a precise schedule on orientation day, which would include mandatory in services, paperwork, and medical issues such as TB testing. The first year's annual budget projects $\$ 98,165$ in operating revenue with $\$ 91,693$ in expenses for a projected gain of $\$ 6,472$. However from a cash flow perspective the program will have a loss of $\$ 1093$ during the first six months due to the lag in insurance payments for services (see cash budget). At the end of the first year, cash flow is 
projected to be a positive $\$ 1,175$. In year two, the projected gain is $\$ 5,907$ on revenues of $\$ 112,189$. If only the start up expenses are considered, the return on investment (Gain from Investment - Cost of Investment divided by the Costs of the Investment) would be positive $(6,472-2500) / 2500)=1.59)$. However, this does not consider the existing resources such as office space, which could be allocated to alternative projects (Appendix D).

Key site support

In discussions with K.C. Nau, MD, Program Director of Family Medicine and Vice Dean of the Eastern Division, and Aaron Henry, MBA, Administrator of Harpers Ferry Family Medicine and Vice President of Finance of the Eastern Division, verbal support for this project has been ongoing. This is based on the Program Director's ongoing support of mental health services in the clinic and the commitment to provide primary care/ behavioral health integration. The creative percentage of fees collected contractual agreement with the clinicians also provides a risk free financial opportunity for the clinic.

Clinic faculty and support staff is also eager for a structured program and for more behavioral health staff to provide services. Because there has been exponential growth in the clinic population and more primary care providers, the need is clear. A letter of support for the project has been given by Mitch Jacques, MD, Dean of West Virginia University’s Eastern Division (Appendix E). 


\section{Evaluation Plan}

Evaluation of the program would be completed based on the objectives previously discussed in this paper. The first objective is program construction and policy. Several measurements will be used. In order to measure satisfaction with the service by the faculty and staff, surveys will be administered by the project manager (Appendices $\mathrm{G}, \mathrm{H}$ ). One survey will be completed prior to the hiring of new clinicians and the start up of new structured program. The follow-up survey will be administered six weeks after the clinicians start. Additionally, satisfaction surveys given to patients will be distributed as they experience the new program (Appendix H). Independent $t$ tests will be used for statistical analysis (Melynk \& Fineout-Overhold, 2005). Other evaluative mechanisms of this objective will be the completion of the policies and a patient admission packet. Policies will address the internal and external referral process, late cancellations and no show, and safety and reporting circumstances related to: harm, safety contracts, emergency resources, and dismissal from the practice due to nonattendance or noncompliance with treatment.

Objective two addresses the clinician and performance. Evaluative measures that will be reviewed will be the amount of time dedicated to patient treatment booked on the providers' schedules and achievement of productivity standards. These measures are now being maintained in the new EPIC system and are easily retrievable for review. These benchmarks will be set by the clinic. In general, a clinician should have a less than $12 \%$ patient no show rate and maintain a $90 \%$ booked schedule. A chart review process monitoring aspects of the behavioral health intervention will also be put into place with appropriate feedback to clinicians. This is a new process for the clinic and standards will 
be set based on CARF accreditation standards. Currently, this evaluative process is measured for the APRN by family practice standards. However, since the new clinicians will only provide mental health services, the format and indicators will change. Some quality indicators may include: elements of the evaluation, diagnostic criteria, and the completeness of the chart. Built into the evaluation processes will be frequent and timely feedback to administration and new clinicians. This will be done through monthly reports. In the past, these reports were difficult to access and often inaccurate. The new system wide computer system provides easy access. Frequent communication during the start up phase is essential for the viability of the program and in assisting the new clinicians in adapting and understanding the new environment.

The final objective, certification, will be delayed indefinably due to a budget shortfall and fiscal constraints. The initial plan was that there would be two measurements. The first completed measurement was certification of the project manager. The completed certification course would be conducted through the University of Massachusetts, Department of Family Medicine and Community Health Certificate Program. This is a 36 hour didactic and interactive training course conducted in six, full day workshops given one Friday a month for six months. The completion of the program by the project manager will be measurable as will the request for the program certification packet from CARF.

\section{Evaluation}

The program evaluation was based on the specific objectives outlined in the proposal. The aim of the first objective was to provide structure to the integrated primary 
care behavioral health program through policies and procedures specific to the service. These policies, which are contained in forms that patients sign at registration, provide both patients and staff with guidelines for the management of unique situations that are related to integrated services such as disclosure, informed consent and safety. The policies were written for patients seen only in the Harpers Ferry Family Medicine integrated primary care behavioral health program and associated clinics where such services may be delivered. Specifically, the policies included counseling policies, privacy policies, informed consent for medication treatment, informed consent for release of information, patient intake form - self information sheet, and telephone appointment reminder consent (Appendices I, J, K, L, M, N).

Prior to submission for approval, the policies were researched from a variety of sources including other practices and WVUH/Chestnut Ridge Hospital outpatient services. Standard forms from behavioral health manuals were also considered (Wiger, 1999; Zuckerman, 2003). Additionally, polices and practices informally used in the program were formalized. For instance, the counseling polices discussed with patients on their first visit by the clinician were now in a written format allowing for clarity between patient and provider.

The target date for the completion and approval of the policies was November, 2008. Approval did not occur until approximately March, 2009. There was a significant delay particularly relevant to the no show policy because, while this was a policy approved for Chestnut Ridge Hospital outpatient service, it had never been approved for a primary care site. All policies were finally approved by corporate compliance but have 
yet to be implemented due to university and system wide priorities that were superseded by the implementation of, and transition to, the new computer system.

Another aim addressed in objective one was the initiation of human resource activities which would prepare for the hiring of the clinician as proposed in the expansion. The objective specified that activities such as paneling and credentialing for insurance purposes, and establishing a contractual fee for a service pay scale would be completed as an evaluative measure. The debate and confusion over the status of clinician's position resulted in extraordinary delays and a significant change in the evaluation process. The inability to hire a contractual employee for the position voided the evaluative processes which had been proposed. Since the clinician would be hired as a part time salaried employee who would not bill for services, no contractual fee schedule, or insurance paneling and credentialing activities were necessary.

The final measure of objective one was the allocation of completed space in which the clinician could see patients. It had been estimated that space would be identified and modified to meet the needs of a behavioral health clinician seeing patients. However, due to faculty and full time staff changes, there was no space available at Harpers Ferry Family Medicine. Space was assigned at a satellite women’s health clinic associated with the main clinic which is part of the clinic system. The total time estimated for this objective to be completed was six weeks. However, the space allocation took four months to complete.

The evaluation process based on objective two was even more complex and addressed the hiring of the clinician. The position of mental health clinician was advertised in the local newspaper and drew only a few applicants (Appendices O, P). A 
master's prepared social worker (MSW) working on licensure as a Licensed Independent Clinical Social Worker (LICSW) responded to the ad (Appendix, Q). The clinician was hired for six hours per week for twelve weeks. The clinician was paid \$32.50 per hour which included FICA tax @ 7.65\%. The clinician worked only eleven weeks because of a personal situation that caused an absence for one week .The total salary for the eleven week period was $\$ 2,145.00$. During the eleven weeks, the clinician was in the clinic for six hours per day. There were a total of sixty counseling appointments available with six hours of unproductive time being used for orientation, computer based learning, and a didactic presentation to the resident staff. Of the sixty available appointments, forty three [72\%] appointments were booked. This is a lesser percentage than was projected in the initial proposal at which time $90 \%$ booked appointments was projected. However, this decrease in booked appointments could be attributed to the change in venue for the clinician and lack of shared office space at the main clinic office. Additionally, of the forty three appointments booked, six patients (7\%) did not come for their appointment, and seven patients cancelled appointments. Based on an estimated rate of $\$ 83.00$ per visit for thirty completed visits, the clinician could have earned $\$ 2490$, slightly above salary. These calculations did not consider what level of payments that payors would approve. However, the computations suggest that a behavioral health clinician could be self supporting.

Pre and post implementation surveys completed by providers, staff, and patients were collected and analyzed as discussed in objective two. The surveys for the providers and staff groups contained five questions and were measured on a seven point Likert scale. The scale weight was $1=$ high to $7=$ low. The analysis of faculty and staff 
responses included perceptions of accessibility of services prior to and after the interventions (Appendices F, G). The surveys for the patient group contained eight questions and were measured on a five point Likert scale. The weight of the scale was 1 $=$ high to $5=$ low. Patient responses included perceptions of satisfaction pre and post implementation (Appendix H). Prior to data analysis, the level of significance was set at $p$ $<0.05$. Independent $t$ - tests were conducted with each group. When no statistically significant differences were found using this statistic, a Cohen's $d$ test was used. While statistical significance is certainly important, it is not necessarily the most important consideration in evaluation research. Effect size is a simple way of quantifying the size of the difference between two groups (Ender, 2003). The difference between the each group was measured by the pre and post tests. Effect size has a particular value in quantifying the effectiveness of a particular intervention which in this project was the clinician (Coe, 2002). Cohen's $d$ evaluates the effect size when comparing two group means, computed by subtracting one mean from the other and dividing by the pooled standard deviation called the standardized mean difference (Polit \& Beck, 2008, p.749). Effect size is important to establish when a study has limited statistical power (Becker, 2000).

Analyses of accessibility by $t$ test in the provider group resulted in $p=.466$, which was not statistically significant. A Cohen's $d$, measuring the mean difference in accessibility resulted in $d=.30$. According to Polit and Beck (2008), when no prior research exists, researchers may estimate the effect size or the magnitude of the effect which can be small, medium, or large (p. 604). A $d$ of .30 is a small effect. Analyses of communication by $t$ test in the provider group resulted in $p=.356$, which was also not statistically significant. However, the effect size as measured by a Cohen's $d$ resulted in $d$ 
$=.41$. This also indicated a small effect. Although indicating only a small effect size, both tests revealed a positive change. Although not statistically significant as indicated in Table 1, the changes indicate an improvement in the perceptions of the providers. These improvements indicated that providers’ perceptions about both accessibility and communication were improved between the pre and post test and indicated that the intervention was effective. 
Table 1. Provider Groups

\begin{tabular}{|c|l|l|}
\hline Question & Pretest & Posttest \\
\hline 1. Access to treatment & Mean (sd) & Mean (sd) \\
\hline 2. Access to emergency mental & $5.07(1.70)$ & $3.27(2.04)$ \\
\hline 3. Timely communication & & $4.5(2.27)$ \\
w/MH providers & $3.57(1.72)$ & $2.81(1.84)$ \\
\hline 4. Status updates on mental & $4.42(1.84)$ & \\
health referrals & & $3.36(2.32)$ \\
\hline providers & & \\
\hline 5. Opportunities for case & $3.21(1.81)$ & \\
\hline
\end{tabular}


Patients’ responses revealed little change with a $p=.101$. A ceiling effect, or cluster of high scores, was noted with this group. This means that the measurement cannot take on a value higher than some limit or ceiling which is imposed by the phenomenon being measured (SMARTPsych, 2009). As a result there is a lack of variability. In the patient surveys, the scores were rated at the high end of the scale. This lack of variance impaired the investigator's ability to measure the true means. 
Table 2. Patient Groups

\begin{tabular}{|l|l|l|}
\hline Question & Pretest & Posttest Mean \\
\hline 1. How long did you wait for appt & $1.45(1.07)$ & Mean (sd) \\
\hline 2. How much have you been helped & $1.45(0.65)$ & $1.0(0)$ \\
\hline with mental health problem? & & $1.11(0.31)$ \\
\hline 4. Courtesy, respect, of provider & $1.09(0.28)$ & $1.11(0.31)$ \\
\hline 5. Visit overall & $1.0(0.42)$ & $1.11(0.31)$ \\
\hline 6. Amount of wait time for $1^{\text {st }}$ appt & $1.81(1.11)$ & $1.0(0)$ \\
\hline 7. Seeing a counselor in your Dr's & $1.09(0.28)$ & $1.33(0.99)$ \\
\hline office? & & $1.11(0.33)$ \\
\hline 8. Mental health treatment overall? & $1.27(0.44)$ & \\
\hline
\end{tabular}


Staff perception of accessibility of the services resulted in $p=.109$, which was not statistically significant. A Cohen's $d$, measuring the mean difference resulted, $d=.71$ indicating a modest effect size and improvement in the findings. Staff perception of communication from pretest to posttest declined, $p=.124$. This value was nonsignificant. A Cohen $\mathrm{d}$ test resulted in $d=.70$ also indicating a modest effect size. While staff perception of accessibility of services did improve, staff perception of communication about the service did decline. The fact that this occurred is not surprising based on the confusion related to the clinician's availability and assigned site. Staff, unsure of the clinician's work hours and duty station, found it necessary to make frequent calls to the satellite office to verify these issues. Additionally the referral process, once hoped to be conducted with ease, became cumbersome for the staff. It became a multistep process involving several staff personal at two different offices. Unfortunately, as with the total process, by the end of the twelve week period, the staff understood the flow, but the pilot test for the service was then over. 
Table 3. Staff Groups

\begin{tabular}{|l|l|l|}
\hline Question & Pretest & Posttest \\
\hline 1. Access to MH appts for adults in practice & $5.2(0.4)$ & Mean (sd) \\
\hline 2. Access to emergency MH for adults in the & $6.4(0.8)$ & $5.18(2.0)$ \\
\hline practice & & \\
\hline 3. Access to MH appts for adults in community & $5.7(1.1)$ & $4.90(2.15)$ \\
\hline 4. Positive comments about counseling in & $1.4(0.8)$ & $2.72(1.48)$ \\
\hline practice & & $3.45(1.55)$ \\
\hline diagnosed w/ MH problems & $3.2(1.6)$ & \\
\hline
\end{tabular}


Additional qualitative data was gathered and revealed positive comments about the intervention. One provider wrote:

ML called twice to discuss concerns she had regarding my patient. I appreciated this and it made me feel like I was better able to care for my patient because of it. Also it was very nice that the patients I referred for behavioral health were seen in a more timely manner during the time when ML was here. A lot of patients don't come in until they are in crisis or almost in crisis. It is often very frustrating when we have to tell them they have to wait six weeks when they need the care today.

The third and final objective dealt with the completion of certification of both clinicians and the integrated program. While this was and is a lofty goal, the previously discussed financial that barriers exist prohibit either process from occurring at this time that have been elucidated in this paper.

\section{Discussion}

\section{Proposal Modifications}

The pilot program, the Evaluation of the Expansion of Behavioral Heath Series in a Primary Care Clinic, was launched in a very different format than was originally proposed. The final capstone project submitted in December 2008 was scheduled to be completed by April 2009. However, the timeline was not achieved because there were 
many barriers and obstacles that were introduced. The project was significantly delayed and the program was greatly modified due to budgetary constraints, a hiring freeze, and space limitations. Clinical, philosophical, financial and organizational barriers continue to hamper integration as described in the literature (Gunn \& Blount, 2009; Robinson \& Strosahl, 2009).

The first objective of the proposal was to formalize the program structure. Policies and documents which were previously lacking were written. These policies included: privacy policies, informed consents for treatment and medications, patient self information forms, counseling policies, and adult assessment forms. Although the forms were accepted and approved by the university compliance office, implementation never occurred (Appendices I, J, K, L M, N). Unfortunately, the planned implementation coincided with the clinic's transition to Merlin, the electronic medical record system within the university. The technical change process was a significant burden for the support staff and, in particular, the front desk staff that are responsible for obtaining patient signatures for consent. Adding new forms to an already cumbersome process would significantly slow the registration process and could cause confusion among staff and patients. While seemingly essential documents to the primary care behavioral health program, the forms represent another difference in the two treatment cultures. It is hoped that in the future, when there is a better understanding of the capabilities of the new electronic system, that these forms may be merged into the system, preloaded in the electronic medical record system, and available to patients upon registration in a more expeditious fashion. 
It is also important to note that the approval process for the forms was not without controversy. The concept of charging a patient for a missed visit, late cancellation, and for a no show, is not consistent with the university system. This practice, although common in behavioral health practice, is not usual and customary in primary care. This is a clear demonstration of differences in treatment philosophies that exist between behavioral health and primary care (Gunn \& Blount, 2009). While a missed visit can be a treatment issue in behavioral health, there is not the same significance in a primary care visit. The additional dilemma of not charging a patient for missed services, then adds a financial burden for the behavioral health provider who is expected to be clinically and financially productive. This is an example of the financial disincentives that face integrated programs (Cummings, O’Donohue, \& Cummings, 2009; Robinson \& Strosahl, 2009).

The second objective of the project identified hiring the clinical staff member whose services would act as the intervention for the expansion process. Reimbursement for the clinician was to be structured on a fee for service basis. This approach to reimbursement would minimize any financial risk for the clinic. This model presupposes that a certified mental health clinician would be reimbursed based on a behavioral health fee schedule. The prerequisite paneling and credentialing required by the organization would facilitate the process of billing and reimbursement. A major obstacle, which prevented this from happening, was the fact that no nonphysician clinician had ever been hired in this manner. Although the capstone project was approved by the administrators at the clinic, the fact that the university corporate affiliate would only hire physicians on a contractual basis emerged at the point of project implementation. This fact was identified 
after approval of the capstone proposal, and was unknown to the Eastern Division administration. This change affected every facet of the program especially the financial aspects. The proposed budget and financial projections were essentially useless because the foundation for the proposal was based on the contractual payment agreement between the corporation, clinic and the clinician. That is, the sustainability of the position would be based on revenues generated and productivity standards that would be set. The clinician would earn a salary based on fees collected from patient visits. However, the clinician was hired as a provider who worked on a temporary, part time basis without billing for the provision of services. Paneling and credentialing by insurance companies was not necessary. There were also no productivity standards set. A masters’ prepared social worker who was preparing for advanced licensure expressed interest in the position even though it was temporary (Appendix Q). This occurred because the clinician wished to experience working in an integrated system. The fact that such a qualified clinician was interested in a short term, timed limited position was very fortuitous. The administrator was able to designate monies from the budget to fund the position on a temporary basis in spite of the current hiring freeze. The clinic hiring freeze was imposed after the proposal was accepted as a pilot program.

A positive outcome from this change was that the clinician was not bound by the fiscal rules of behavioral health care. That is, there were no limitations on visits and no precertification necessary for visits necessary. Patients who had no behavioral health insurance benefits could be seen without regard to insurance issues. This allowed patients to be seen emergently and in a less traditional format. For instance, in the current primary care behavioral health structure, patient cannot be seen on the same day by both the 
primary care provider and the behavioral health clinician. Rules such as this, mandated by payors, hamper the provision of care. The change in the pilot project permitted the clinician to function in the role of behavioral health consultant as described by Robinson \& Reiter, (2007; Pomerantz, Coson, \& Detzer, 2009; Robinson \& Strosahl, 2009). While this behavioral health consultant role is discussed in the literature and promoted, it is often not possible because of financial disincentives. Ideally, the behavioral health consultant in this role employs brief solution focused counseling in a one to four visits to facilitate health rather than psychotherapy to ameliorate symptoms (Robinson \& Reiter, 2007; Walker \& Collins, 2009). Byran, Morrow, and Appolino (2009) believe that brief psychological interventions can be the most effective intervention in an integrated setting (Appendix R).

Another pitfall was the lack of space at the main primary care site. This organizational barrier is a very practical one and understandable. The inability to make room for behavioral health services highlights the culture differences since primary care services do seem to be more highly valued than the process oriented behavioral health interventions (Gunn \& Blount, 2009). One might speculate that this is the diminishing of behavioral health services and a continuation of the dichotomous practice patterns representing a mind body split (Lipsitt, 1997). An example of the cultural differences between primary care and behavioral health is office arrangement. The office setting for the primary care provider is an exam room while the usual office setting for the behavioral health provider can look like a living room (Maine Health, 2009).

At Harpers Ferry Family Medicine, expansion of the residency program and the addition of several new faculty providers left little room for another behavioral health 
provider to see patients. Therefore, the clinician was assigned to a satellite clinic within the system. This reassignment was another factor that greatly impacted the outcome of the pilot project and project evaluation. As a result, with the clinician not being in plain view, staff and faculty had to be reminded of her availability. This factor did hamper the referral process. However, faculty providers who regularly worked at the satellite clinic used the service and were pleased with the clinician's availability. Patients who completed the satisfaction questionnaire expressed satisfaction with the service, but also often expressed disappointment because the clinician would be available for such a brief period.

Colocation and dropout are important topics discussed in the literature (Blount, 2003; Robinson \& Reiter, 2007). Colocation is common vernacular in integrated settings and implies that both behavioral health and medical providers are located in the same offices and share resources (Blount, 2003). This was demonstrated in the pilot project when patients who were referred from the main clinic to the satellite office did not follow through for appointments (Appendix S). Not all the patients who were referred for services were seen. Blount (2003) reports that colocation is an important factor in the success of integration. Craven \& Bland (2006) identify that collaborative practice is most effective when there is colocation. Gunn \& Blount (2009) remind readers that colocation is desired but not the norm.

While dropout may be attributed to lack of colocation, patient barriers should not be overlooked. During the primary care visit, patients will often agree to see the behavioral health provider for several reasons (Lacy, Paul, Reuter, \& Lovejoy, 2004). One reason is because patients are truly in psychological distress. Another reason may be 
that patients want to please their doctor. Time and distance between appointments, a patient's own denial of the behavioral health problem, and stigma that accompanies mental illness are variables that put the patient at risk for dropout (Goldman, Brody, \& Wise, 1998; Mitchell \& Selmes, 2007).

The final phase of the project, which proposed certification for the clinicians and program, was indefinitely postponed because of finances. The cost / benefit ratio to complete these certifications was not seen as feasible. Any clinician who wishes to do this certification may incur the cost independently without reimbursement from the clinic. While this financial barrier is understandable in the wake of the economic environment, the process of primary care behavioral health integration can move forward only with trained clinicians who understand the operation of a model which is different from pure behavioral health (Robinson \& Reiter, 2007; Zoberi, Niemiec, \& Margolis, 2008). Gunn \& Blount (2009) strongly support the need to increase the knowledge base and skills for those working in the specialized field of primary care mental health because this field is so distinct from specialty care. In a recent report by Robinson and Strosahl (2009) training of both primary care providers as well as behavioral health consultants is deemed necessary in order to truly grasp and implement integration. Blount \& Miller (2009) caution that without properly trained behavioral health clinicians integrated programs could fail. Certification of the primary care behavioral health program, similar to Joint Commission Accreditation, and of the clinician by a certification program would bring a great deal of credibility to the clinic. Certification often is equated with expert knowledge by both consumer and health care provider. 


\section{Study Limitations}

There were several limitations to the study. A major limitation was the lack of survey participants to study the true impact of the pilot project. That is, the number was small which often leads to nonstatistically interpretable results. Polit and Sherman (1990), however, report that nonstatistical findings are a common occurrence in both published and unpublished nursing research. Lack of statistical power can lead to mistakes and inconsistent results reflecting Type II errors (Pilot \& Beck, 2008, p. 602). Power refers to the probability that a test will be statistically significant when such a difference actually exists, rejecting the null hypothesis (Zint \& Montgomery, 2008). When the sample size increases, so does the statistical power of the test . However, when a difference between groups is found, but does not actually exist, errors do occur (Zint \& Montgomery, 2008).

Another significant limitation of the study was the flawed design, in that study participants were not matched at pre and post test on the surveys. Therefore, paired $t$ tests were not completed. One reason for unmatched groups was the fact that clinic staff who instructed patients on how to do the survey, changed during the pre and post survey. That is, patients did not always receive a survey either prior to or after implementation of the pilot project in spite of an educational session and reminders to staff. The fact that staff at two different sites were dealing with a new behavioral health clinician at a different location may be a reason for the negative results in the post test analysis of staff, as the process became cumbersome. Clearly, communication about the clinician's availability and how to make a referral became challenging. 
A short time line added to the limitations and the pilot project may have been more successful given a longer period for implementation. The confusion about the availability of the clinician at another site may have been eased over time. Patient referrals may also have increased as staff and providers became more familiar with the new process. In part, the short time line was due to budgetary constraints. There was a small time period when the clinician could be hired and paid a salary. The clinic administrator was able to dedicate funds from an unfilled staff position in order to fund the clinician's part time position. This position would end in the new fiscal year. Acting as a “champion” as identified by Walker \& Collins (2009), the clinic administrator understood the value of the pilot project, sought to decrease the barriers encountered, and was cognizant of the benefit that integration brings to the patients in the clinic.

Another limitation which hampered the study was confusion about the survey questions, which lacked clarity, validity and reliability. Some of the questions were vague and did not specifically address accessibility and communication. One example is that one provider on a post implementation survey gave a low score to the communication question but noted that the clinic mental health clinician was the exception. It was noted that there was good communication between the provider and the behavioral health clinician in the clinic but that communication with community behavioral health providers was lacking.

\section{Application of Theoretical Framework}

The proposed practice change demonstrated by the pilot program was guided by Lewin's Three Step Change Theory. In this theory, Lewin, believed an issue is held in 
balance by the interaction of two opposing sets of forces (Lewin, 1951). Forces seeking to change the system were labeled as driving forces, and those against the change, restraining forces (McEwen \& Willis, 2007). Lewin believed that organizations are systems in which the present situation is not a static pattern but a dynamic balance of forces working in opposition (Lewin, 1951). In order for change to occur, the driving force must exceed the restraining force. This component of Lewin's theory is called force field analysis (Hershey, Blanchard, \& Johnson, 1996).

Three key concepts have been identified in Lewin’s theories that make planned change occur: unfreezing the status quo, moving to a new state, and refreezing the change to make it permanent (Hershey, Blanchard, \& Johnson). In the unfreezing stage of this project, the problem identified was the lack of sufficient behavioral health services to meet the needs of the clinic population. The need for change was communicated to clinic management, staff and providers. A proposal was submitted that defined the proposed change. Discomfort arose from the unknown, among the administrators of the clinic and Eastern Division of West Virginia University particularly regarding the revenue generating potential of a newly hired clinician. A major obstacle occurred when it was discovered that, due to fiscal constraints in the clinic, the clinician would have to be employed rather than have contractual status.

For planned change to successfully occur, it is important to unlock the status quo (Kassean \& Jagoo, 2005). The unfreezing phase which was planned in the initial project proposal was not followed because of the change in the hiring status of the clinician.

The moving or change phase occurred when the clinician was hired and began providing services. Referrals were appropriately directed to the clinician. An evaluation 
of the services occurred at twelve weeks after the inception of the expansion. Surveys were given to patients regarding the availability of services and their satisfaction with the services (Appendix H). Line and support staffs were encouraged to give feedback regarding the different aspects of the program.

Hypothetically, in the refreezing phase of the capstone project, final change will be recognized. Unfortunately, because the clinician position was a temporary, part time position, services were provided for only twelve weeks and the expansion was not sustainable. Change in any system is challenging. The integration of behavioral health into primary care, which is a major change in the way that health care is delivered, is a challenging task. One might imagine the metaphor in this change process as primary care as the restraining force and behavioral health as the driving force, with the end result being an expanded integrated program.

\section{Recommendations}

This pilot study, which aimed to expand already existing behavioral health services in a primary care clinic, supports the literature on this topic and holds promise for future expansion of services. Mistakes were made and lessons were learned. The problems that arose will assist in the design of a more efficient and profitable expansion of behavioral health services in the future with a particular focus on financial issues. An opportunity to experience expanded behavioral health consultation services was presented, and permitted a comparison of current practice to an expanded model.

The comparison of the current practice and the updated model reminded the author that an integrated primary care behavioral health service has existed at Harpers 
Ferry Family Medicine for ten years. Although lacking high levels of integration, there was great vision, intent, commitment and determination by providers and administration to make the program successful(Doherty, McDaniel, \& Baird, 1996). A major strength has been high levels of collaboration built on existing trusting relationships (Craven \& Bland, 2006). In 1999, the concept of integration was cutting edge in West Virginia. The program has served many patients and was structured on a traditional behavioral health model because that is all that was known at the time. It was designed without toolkits, manuals, textbooks and evidence based practice guidelines. However, through knowledge and experience gained in the past ten years there have been continued efforts to refine the way interventions are conducted with patients. Additionally, there continues to be a concerted effort in refining the collaborative process through frequent provider to provider conversation. Colocation is an accepted component in this integrated program as plans for a new satellite clinic include an office for a behavioral health counselor. New health and behavior billing codes hold promise for a brighter financial future (Kessler, 2006).

Implementing change is a laborious process as demonstrated in this pilot project. In his conceptual model of integration, C.J. Peek posits that in order for an integrated system to be successful there must be an alignment of the clinical, organizational, and financial systems (Peek \& Heinrich, 1995). All of these components must be considered when attempting integration. It was clear that an attempt to align those systems in the pilot project occurred but barriers that have been explicated in this paper were experienced and impeded the process. Serious consideration must be given to barriers that prevent true integration from occurring, such as appointment schedules, patient flow, 
treatment settings, financial disincentives and philosophical differences (Gunn and Blount, 2008; Maine Health, 2009). Walker and Collins (2009) report that true integration is quite challenging and that totally integrated programs are rare. In a recent publication by the AHRQ (2008) reviewing RCT and high quality quasi -experimental design studies for integrated care components, the outcomes were positive but lacked consistency in models, approaches, and levels of integration. AHRQ recommendations included removing obstacles and barriers, creating incentives, and mandating integration (2008, p.vi).

\section{Conclusion}

It is clear that primary care behavioral health integration is effective but meets significant challenges at this time. The literature is robust in support of such practices. This pilot study guided by Kurt Lewin’s Three Step Change Theory, proposed an expansion of behavioral health services in a primary care clinic. The proposal outlined three objectives upon which the pilot would be completed: (1) program design and structure; (2) clinician hire; and (3) certification. A literature review revealed supporting evidence of integrative and collaborative care. However, reports have emerged stating there is a lack of consistency in models, approaches and levels of integration (AHRQ, 2008). The proposal was based on a descriptive, longitudinal design evaluating the expansion of the behavioral health services and satisfaction of the stakeholders. Surveys were used to gather data. Although the data did not show significance, positive changes were noted. 
Unexpected advantages of the pilot project provided a glimpse into more diversified services with an added staff member and the associated benefits that were afforded to patients. The project presented a traditionally trained behavioral health clinician the opportunity to experience a new approach to behavioral health consultation and permitted the author the opportunity to observe the practice change. It is the intent of this author to continue the movement towards expanding the service as more patients adopt the clinic as their medical home with increased demand for integrated services. Integrated behavioral health is no longer just an idea or a model; it is a movement whose time has come. 


\section{References}

Agency for Healthcare Research and Quality. (2008). Integration of mental health/ substance abuse and primary care. Washington, DC: US Department of Health and Human Services accessed at http://www/ahrq.org on 8/6/09.

American Academy of Family Physicians. (1999). Family physician, scope, philosophical statement. AAFP Reference Manual. Leawood, KS: American Academy of Family Physicians.

American Academy of Family Physicians. (2001). Mental health care services (position paper). AAFP Reference Manual, Leawood, KS: American Academy of Family Physicians.

Arvantes, J. (2008). Experts call for integration of primary care with mental health, substance abuse services. AAFP News Now Retrieved from http://www.afp.org/online/en/home/publications/new/news-now/professionalissues/2008.htm on 4.27.08.

Becker, L. (2000). Effect size lecture notes. University of Colorado website: http://www.uccs.edu/ faculty/lbecker/.

Berry, L., Selders, K., \& Wilder, S. (2003). Innovation in access to care: a patient centered approach. Archives of Internal Medicine, 139, 568-574.

Blount, A. (Ed.). (1998). Integrated primary care: the future of medical and mental health collaboration. New York, NY: Norton.

Blount, A. (2003). Integrated primary care: organizing the evidence. Families, Systems \& Health, 21, 121-134.

Blount, A. \& Miller. B. (2009) Addressing the workforce crisis in integrated primary 
care. Journal of Clinical Psychology in Medical Settings, 16, 1, 113-119.

Bower, P. \& Sibbald, B. (2003).On - site mental health workers in primary care: effect on professional practice. Cochran Database Systematic Review. (3) CD002969.

Bryan, C., Morrow, C., \& Appolonio, K. (2009). Impact of behavioral health consultant interventions on patient symptoms and functioning in an integrated family medicine clinic. Journal of Clinical Psychology, 65, 3, 281-293.

Canadian Collaborative Mental Health Initiative. (2006). Collaboration between mental health and primary care services: a planning and implementation toolkit for healthcare providers and planners. Mississauga, Ontario: Canadian Collaborative Mental Health Initiative.

Coe, R. (2000). What is an “effect size”. Retrieved from CEM, Durham University website @ http://www.cemcenre.org/renderpage.as?linkID=30325016 on 11.13.09.

Commission on Accreditation of Rehabilitation Facilities. (2009). Behavioral health standards manual. Washington, DC: CARF.

Craven, M. \& Bland, R. (2006). Better practices in collaborative mental health care: an analysis of the evidence base. Canadian Journal of Psychiatry, 51, 1. Retrieved from www.ccmhi.ca. on 10.1.08.

Cummings, N., O’Donohue, W., \& Cummings, J. (2009). The financial dimension of integrated behavioral /primary care. Journal of Clinical Psychology in Medical Settings, 16, 31-39.

deGruy, F. ( 1996). Mental health care in the primary care setting. Primary Care: America's Health in a New Era. Washington, DC: National Academic Press.

Doherty, W., McDaniel, S., \& Baird, M. (1996). Five levels of primary care/behavioral 
healthcare collaboration. Behavioral Healthcare Tomorrow, October, 25-28.

Ender, P. (2003). Effect size. Introduction to research statistics and design. Retrieved from UCLA Department of Education: http://www.gseis.ucla.edu/courses/ed230a2/notes/effect.html on 11/4/09.

Engel, G. (1977). The need for a new medical model: a challenge for bioscience. Science, 196, 129.

Farrar, S., Kates, N., Crustili, A., \& Nikolaou, L. (2001). Integrated model for mental health: are providers satisfied with it? Canadian Family Physician, 47, 24832488.

Gallo, J., Zibrisky, J., Nazar, M., Bogner, H., Quiyano, L. et al. (2004). Primary care clinicians evaluated integrated and referral models of behavioral health care for older adults: results from a multisite effectiveness trial (PRISM-e). Annals of Family Medicine, 2, (4) 305-309.

Goldman, L., Brody, D. \& Wise, T. (1998). Psychiatry for primary care physicians (1 $1^{\text {st }}$ ed.). Chicago, IL: American Medical Association.

Graham, R (2007). The patient-centered home: history, seven core features, evidence and transformational changes. Washington, DC: Robert Graham Center.

Gunn, W. \& Blount, A. (2009). Primary care mental health: a new frontier for psychology. Journal of Clinical Psychology, 65, (3), 235-252.

Hazelbaker, C. \& Halls, C. (2006). The swot analysis: simple, yet effective. Athletic Therapy Today, 11, (6), 53-55.

Henning, A. (2000). A systematic review of the effectiveness of brief psychological counseling therapies in primary care. Families, Systems \& Health, 18, 3, 279-314.

Hirschfield, R. (2003). The mood disorder questionnaire: a simple patient rated screening 
instrument for bipolar disorder. Primary Care Companion to the Journal of Clinical Psychiatry, 4, (1), 9-11.

Hershey, P., Blanchard, K., \& Johnson, D. (1996). Management of organizational behavior ( $7^{\text {th }}$ ed.). Upper Saddle River, NJ: Prentice -Hall.

Hodges, B., Inch, C., \& Silver, I. (2001). Improving the psychiatric knowledge, skills, and attitudes of primary care physicians, 1950-2000: a review. American Journal of Psychiatry, 158, 1579-1586.

Horn, S. (2003). Limiting access to psychiatric services can increase total health care costs. Journal of Clinical Psychiatry, 64, (17), 23-28.

Integrated Primary Care. (2009). Certificate program in primary care behavioral health. Retrieved on November 6, 2009 from University of Massachusetts Medical School, Department of Family and Community Medicine website @ http://umassmed.edu/fmch/index.aspx.

Kahn, N. (2004).The future of family medicine: a collaborative project of the family medicine community. Annals of Family Medicine, 2, S3-S32.

Katon, W., Roy-Byrne, P., Russo, J., \& Cowley, D. (2002). Cost -effectiveness and cost offset of a collaborative care intervention for primary care patients with panic disorder. Archives of General Psychiatry, 59, 1098-1104.

Kassen, H. \& Jagoo, Z. (2005). Managing change in the nursing handover from traditional to bedside handover-a case study from Maritius. BMC Nursing 4, 1, 1472-6955-4-1. [Electronic version].

Kates, N., Fugere, C., \& Farrar, S. (2004). Family physician satisfaction with mental health services: findings from a community survey. CPA Bulletin, 10-14.

Kessler, R. (2006). Integration of care is about money too: The health and behavior codes 
as and element of a new financial paradigm. Families, Systems, and Health, 26, (2), 207-216.

Kessler, R. (2009). Identifying and screening for psychological and comorbid medical psychoogical disorders in medical settings. Journal of Clinical Psychology, 65, (3), 253-267.

Klinkman, M. (2003). Role of alogorithms in detection and treatment in primary care. Journal of Clinical Psychiatry, 64,19-23.

Lacy, N., Paul, A., Reuter, M., \& Lovejoy, B. (2004). Why we don’t come: patients' perceptions on no - shows. Annals of Family Medicine, 2, 541-545.

Lefevre, F., Reifler, D., Lee, P., Sbenghe, M., Nwadiaro, N., Verma, S. et al. (1999). Screening for undetected mental disorders in high utilizers of primary care services. Journal of General Internal Medicine, 14, (7), 425-431.

Lewin, K. (1951). Field theory in social science. New York, NY: Harper \& Row.

Lipsitt, D. (1997). From integration to fragmentation: a history of comprehensive patient care. In J. Haber \& G. Mitchell, (Eds.), Primary care meets mental health. Tiburon, CA: Centralink.

Liu, C., Hendricks, S., Chaney, E., Heagery, P., Felker, B., Hasenberg et al, (2003 Cost effectiveness of collaborative care for depression in a primary care veteran population. Psychiatric Services, 54, 698 -704.

Maine Health. (2009). A practical guide to mental health integration. Maine Health. Retrieved from www.ruralhealthweb.com/index.cfm?objectid=6EAF6313-11856B66-88B535E2D89B3334. 
McClusky, A. \& Cusick, A. (2001) Strategies for introducing evidence-based practice and changing clinician behavior: a manager's toolbox. Australian Occupational Therapy Journal, 49, 63-70.

McEwen, M. \& Willis, E. (2007). Theoretical basis for nursing, ( $2^{\text {nd }}$ ed). Philadelphia, PA: Lippincott, Williams \& Wilkins.

Melynk, B. \& Fineout- Overhold, E. (2005). Evidence - based practice in nursing and healthcare: a guide to best practice, ( $1^{\text {st }}$ ed.). Philadelphia, Pa: Lippincott.

Mental Health, United States. (2004). Available at http://mentalhealth.samsha.gov/publications/allpubs/SMA06-4195/default.asp.

Mitchell, A. \& Selmes, T. (2007). Why patients don’t attend their appointments: maintaining engagement with psychiatric services. Advances in Psychiatric Treatment, 13, 435-437.

Morehead, P. (2006). New American Webster Handy College Dictionary,. (4 ${ }^{\text {th }}$ ed.). New York, NY: Signet.

New Commission on Mental Health. ( 2002). Achieving the promise: transforming mental health care in America. The final report. Rockville, MD: DHHS.

Petterson, S., Phillips, B., Bazemore, A., Dodoo, M., Zhang, X. \& Green, I. (2008). Why there must be room for mental heath in the medical home. American Family Physician, 77, 6, 757.

Peek, C. \& Heinrich, R. (1995). Building a collaborative healthcare organization: from idea to invention to innovation. Family Systems Medicine, 13, 327- 342. 
Polit, D. \& Beck, C. (2008). Nursing research: generating and assessing evidence for nursing practice $\left(8^{\text {th }}\right.$ ed.). Philadelphia, PA: Lippincott, Williams \& Wilkins.

Polit, D. \& Sherman, R. (1990). Statistical power analysis in nursing research. Nursing Research, 39, 365-369.

Pomerantz, A., Corson, J., \& Detzer. (2009). The challenge of integrated care for mental health: leaving the 50 minute hour and other scared things. Journal of Clinical Psychology in Medical Settings, 16, 40-46.

Reiger, D., Narrow, W., Rae, D., Mandersheid, R. Locke, B., \& Goodwin, F. (1993). The defacto U.S. mental health and addictive disorders service system. Archives of General Psychiatry, 50, 85-94.

Robinson, P. \& Reiter, J. (2007). Behavioral consultation and primary care: a guide to integrating services. New York, NY: Springer.

Robinson, P. \& Strosahl, K. (2009). Behavioral health consultation and primary care; lessons learned. Journal of Clinical Psychology in Medical Settings, 16, 1, 58-71.

SMARTPsych. (2009). Ceiling Effect. Psychology statistics/methods. Retrieved from the University Of Washington, Department Of Psychology at http://courses.washington.edu/smartpsy/glossary.htm on 11/7/09.

Spitzer, R., Kroenke, K., \& Williams, J. (1999).Validation and utility of a self report version of PRIME-MD: PHQ primary care study. Journal of the American Medical Association, 282, 1737-1744. 
Strosahl, K. (1998). Integrating behavioral health and primary care services: the primary mental health care model. In A. Blount, (Ed.). Integrated primary care: the future of medical and mental health collaboration. New York: W. W. Norton.

Tovian, S. (2009). Integrated health care-one stop shopping. American Psychological Association. Retrieved from http://www.newswise.com/articles/five-questions on $\underline{11 / 5 / 09}$.

Tylee, A. \& Gandhi, P. (2005). The importance of somatic symptoms in depression in primary care. Primary Care Companion of the Journal of Clinical Psychiatry, 7, 167-176.

Unutzer, J., Katon, W., Callahan, C., Williams, Hunkeler, E., Harpole, L. et al. (2002). Collaborative care management of late-life depression in the primary care setting: a randomized control trial. Journal of the American Medical Association, 288, 2836-2845.

US Department of Health and Human Services. (1999). Mental health: a report of the Surgeon General. Rockville, MD: US Department of Health and Human Services.

Walker, B. \& Collins, B. (2009. Developing an integrated primary care practice: strategies, techniques, and a case illustration. Journal of Clinical Psychology, 65, 268-280.

Wiger, D. (1999). The clinical documentation sourcebook, $\left(2^{\text {nd }} e d.\right)$. New York, NY: Wiley.

World Health Organization. (2001). The world health report 2001: mental health: new understanding, new hope. Geneva, Switzerland: World Health Organization. 
Zint, M. \& Montgomery, N. (2008). Power analysis, statistical significance, \& effect size. Retrieved from the University of Michigan, Department of Education website @ http://meera.snre.umich.edu/plan-onevaluation/plonarticlemultipage.2007-10-30-.3630902539/power-analysisstatistical-significance.

Zoberi, K. Niemiec, R., \& Margolis, R. (2008). Teaching integrated behavioral health in a primary care clerkship. Medical Teacher, 30, e218 - e223.

Zuckerman, E. (2003). The paper office, $\left(3^{\text {rd }}\right.$, ed). New York, NY: Guilford. 
Appendix A: Certificate Program in Primary Care Behavioral Health

\section{Rationale for the Program:}

If the integration of behavioral health clinicians into primary care continues to grow and spread as fast as it has in the last three years, the US will shortly face a staffing crisis. The number of training programs turning out new behavioral health professionals who have the skills to work in primary care is woefully inadequate. And training is necessary. Programs that have transferred mental health professionals straight from specialty mental health centers into primary care have often failed in the past. A transitional experience is needed to give trained mental health professionals the substantive orientation they need to become behavioral health professionals in primary care.

The Department of Family Medicine and Community Health has been training mental health professionals to provide services in primary medical care settings for over fifteen years. In January of 2007, the Department launched a program designed to train mental health professionals to function successfully as behavioral health clinicians in primary care. The program consists of 36 hours of didactic and interactive training. The program is delivered in 6 full-day workshops, one Friday per month for six months. If a participant must miss a scheduled workshop, the material and the credit can be made up by listening to a recording of the session. Participants who complete the whole program receive a Certificate of Completion. Teaching is done by members of the Department of Family Medicine and Community Health of the University of Massachusetts Medical School (see page 2 for a complete listing).

\section{Cost:}

The tuition for the program is $\$ 1600$ per person (fee subject to change without notice), and is due prior to the first workshop in the series. Interested professionals should contact Melissa McLaughlin at McLauM01@ummhc.org 
Appendix B

\section{Behavioral Health customer service unit}

Behavioral Health programs include services to persons or families with needs related to mental illness, alcohol or other drug usage, and other addictions, such as gambling. The services may address relationship or adjustment concerns, domestic violence, and other family issues. The services may be designed to prevent potential problems and treat existing ones. Behavioral health programs are provided in a variety of settings ranging from clinics and inpatient locations to the home, school, community, or criminal justice settings.

Behavioral Health program descriptions (PDF)

Business and Services Management Network program descriptions (PDF)

Frequently asked questions

Opioid Treatment Program

$\underline{\text { Accreditation and standards }}$

$\underline{\text { Discounted insurance premiums for qualified providers }}$

Register for Behavioral Health seminars online

Order the Behavioral Health standards manual and other publications online

Learn more about the Value of CARF Accreditation (PDF)

Go to Promising Practices newsletter (Behavioral Health)

Accredited providers may download a CARF, CARF Canada, or CARF-CCAC logo to display on their website and printed materials.

Visit CARF Canada

Additional resources:

The HIPAA Security Rule: CMS' enforcement activities acquire teeth by Robin A. Johnson. The Security Rule requires covered entities to protect the confidentiality, integrity, and availability of its "electronic protected health information."

Copyright CARF (C) 2009. All rights reserved. 
Appendix C: Force Field Analysis

\begin{tabular}{|l|l|}
\hline Driving Forces & Restraining Forces \\
\hline Increased demand for services @ & Continued primary care mindset by \\
HFFM & Administration \\
Lack of time with current provide & Lack of space at facilities \\
Increased demand for services @ & Lack of BH management expertise \\
Other offices -medical/surgical, & Low reimbursement rates for \\
Maternity center & BH services vs. PC services \\
APRN will lead change project & Management concerns regarding \\
Dean's support & hiring more BH FTEs \\
Eight years of success with current & \\
program & \\
Program Director's commitment to & \\
PC/BH integration & \\
& \\
& \\
\hline
\end{tabular}


Appendix D: Proforma Budget for Behavioral Health Clinicians

\section{Revenue}

Gross Patient Revenue

Deductions

Net Patient Revenue

Total Operating Revenue

\section{Operating Expenses}

Contract Services

UHA Operations Support

$(10 \%)$

Deans Support (10\%)

Non-Capital

Furniture/Equipment

Recruitment/Advertising

Miscellaneous Expense

Provider Tax

Bad Debt Expense

Total Operating Expenses

Total Gain I (Loss)
2 staff $X 20$ sessions each $\times 48$

weeks

$X \$ 100$ less an estimated 15\% no show rate

$\$ 57,120.00$

Deduction to approximate average

insurance payment of $\$ 65$

$\$ 106,080.00$

$\$ 106,080.00$
$\$ 63,648.00$

$\$ 10,608.00$

$\$ 10,608.00$

\$ $2,000.00$

$\$ 500.00$

$\$ 500.00$

$\$ \quad 604.66$

$\$ 5,304.00$

$\$ 93,772.66$
$60 \%$ of patient revenue paid to clinicians

Desk/chair/computer

$.6 \%$ of patient revenue

Assumes $5 \%$ of net patient revenue is not collected 


\title{
Appendix E
}

\author{
WestVirginiaUniversity \\ Robert C. Byrd Health Sciences Center
}

April 15, 2008

Lisa Hardman, DNP

WVU School of Nursing

PO Box 9630

Morgantown, WV 26506

Re: Capstone project for Carolyn Donovan, DNP Candidate

Dear Dr. Hardman:

This letter is to support Carolyn Donovan's Capstone project for her DNP degree. Primary care offices throughout West Virginia generally lack behavioral counseling services. Carolyn has suggested a project to expand behavioral health services at rural clinics using a contracted model for services.

The Eastern Division will be happy to provide space, scheduling, and other similar support necessary to accomplish this project. We will gladly support this project and feel that if shown to be effective it could positively impact patient care in rural areas.

Sincerely,

$\overbrace{}^{2}$, , ,

$\Lambda$

)

C.H.M. Jacques, MD, Phx

Associate Vice President Health Sciences

Dean, Eastern Division 
Appendix F

\section{West Virginia University}

Harpers Ferry Family Medicine

Provider Survey

Can you rate the extent to which the following present problems to you when handling individuals with mental health problems in your practice?

$$
\text { ( } 1 \text { = no problem, } 7 \text { = severe problem) }
$$

1.) Access to (or waiting time for) treatment for individuals needing psychotherapy

$\begin{array}{lllllll}1 & 2 & 3 & 4 & 5 & 6 & 7\end{array}$

2.) Access to emergency mental health assessments for adults

$\begin{array}{lllllll}1 & 2 & 3 & 4 & 5 & 6 & 7\end{array}$

3.) Timely communication with mental health providers

$\begin{array}{lllllll}1 & 2 & 3 & 4 & 5 & 6 & 7\end{array}$

4.) Access to information concerning the status of patients referred for mental health care

$\begin{array}{lllllll}1 & 2 & 3 & 4 & 5 & 6 & 7\end{array}$

5). Opportunities to discuss cases with a mental health professional (counselor, social; worker, nurse, psychologist)

$\begin{array}{lllllll}1 & 2 & 3 & 4 & 5 & 6 & 7\end{array}$

Adapted from Collaboration between mental health primary care services: a planning and implementation toolkits for health care providers and planners. February 2006. 


\section{Appendix G}

\section{West Virginia University \\ Harpers Ferry Family Medicine \\ Consumer Satisfaction Survey}

Here are some questions about the visit you just made. In terms of your satisfaction, how would you rate each of the following?

Excellent Very Good Fair Poor

How long you waited to get this appointment?

How much has the person you see for mental health care helped you with your problems?

The technical skills (knowledge, thoroughness, competence) of the person you saw?

$\begin{array}{lllll}1 & 2 & 3 & 4 & 5\end{array}$

1

2

3

4

5

The personal manner (courtesy, respect,

1

2

3

4

5 sensitivity, friendliness) of the person you saw?

This visit overall?

1 2

3

4

5

1

2

3

4

5

Here are some questions about your mental health care in general. In terms of your satisfaction, how would you rate each of the following?

\section{Poor}

Excellent Very Good Fair

The amount of time you had to wait for your

first appointment with a therapist/counselor?

Being seen for mental health care in your

family physician's office?

1

1

2

3

4

Your mental health treatment overall?

1

2

3

4

.

Adapted from Collaboration between metal health primary care services: a planning and implementation toolkit for health care providers and planners, 2006. 
Appendix $\mathrm{H}$

\section{West Virginia University}

Harpers Ferry Family Medicine

\section{Staff Survey}

Can you rate the extent to which the following present problems to you when handling individuals with mental health problems in the practice? $(1=$ no problem, 7 = severe problem)

1.) Access to appointments for adults needing counseling within the practice

2.) Access to emergency mental health assessments for adults in the practice

3.) Access to appointments for adults within the community referred for mental health care 1

$\begin{array}{llllll}2 & 3 & 4 & 5 & 6 & 7\end{array}$

4.) Positive patient reports that counseling services are offered in this clinic

$\begin{array}{lllllll}1 & 2 & 3 & 4 & 5 & 6 & 7\end{array}$

5.) Difficulty dealing with patients who are identified as having a mental health problem

$\begin{array}{lllllll}1 & 2 & 3 & 4 & 5 & 6 & 7\end{array}$

Adapted from Collaboration between metal health primary care services: a planning and implementation toolkit for health care providers and planners, 2006. 


\section{Appendix I}

\section{UHA - Harpers Ferry Family Medicine Integrated Behavioral Health Services Counseling Policies}

Harpers Ferry Family Medicine Integrated Behavioral Health Services (IBHS) offers brief, solution-focused - counseling services. A referral from your provider will alert our front desk staff to provide you with the opportunity to make an appointment with the mental health provider after signing this document. At the initial assessment session, the mental health provider will assist you in defining your concerns and establishing a treatment plan. If at any point it is established that another service outside the clinic may be more suitable, you will be assisted in identifying more appropriate resources.

Please arrive promptly for your appointments. A late arrival of 15 minutes or more, without notification and approval, will be considered a late cancellation and will result in a fee of $\$ 35$. Missed appointments reduce our ability to provide services to other patients. If you are unable to keep your appointment, you must cancel at least 24 business hours in advance. $A$ fee of $\$ 35$ will be charged for no-shows. To cancel your appointrnent, you must speak to a scheduler during work hours. Cancellations left on voicemail overnight or on weekends will result in a fee of $\mathbf{\$ 3 5}$. Failure to pay the fee may prevent you from receiving further behavioral health services until the fee is paid. Repetitive no-shows or late cancellations may lead to dismisssal from behavioral health scrvices.

Psychiatric medications may be prescribed by nurse practitioners who specialize in behavioral health. Risks and benefits of the medications will be discussed with you as well as side effects. It is the responsibility of the patient to request medication refills in a timely manner. Please contact your phamacy, which will in turn call the clinic with the request. A 72 hour time period is required. Neither the clinic nor the provider is responsible for monitoring refills. Routine medication refills are authorized only during regular clinic hours. Do not contact the doctor on call for medication refills.

Patients who are on maintenance medications are required to be seen at the minimum of twice yearly. Some patients whose medications require lab tests may be seen more frequently. Patients who neglect to keep the required follow up appointments will not receive refills.

Every effort is made to verify insurance coverage. Somc insurance companies do not cover mental health benefits. Ultimately, it is the patient's responsibility to contact their insurance company to verify coverage. Patients will be required to sign a payment waiver. The mental health billing specialist is available to assist you with any questions you may have about this policy.

Harpers Ferry Family Medicine is a training site. Medical students, family medicine residents and nurse practitioner

C:LDocuments and SettingsidonovanclLacal Scttings Temporary Internet FileshoLK7ALBMFD_Counscling_Policics.doc

171 Taylor Strect (Boitivar)

Ilarpers Ferry, WY 25425

(304) $535-6343$ ph (304) $535-66.18$ fax students may sometimes participate in patients" counseling sessions as part of their learning experience. Their obsetvation is important to their education. However, if you are uncomfortable with this, please feel free to discuss with the provider.

In keeping with ethical standards and federal law, all information is kept confidential except as outlined in the NOTICE OF PRIVACY PRACTICES that you are requested to endorse. The professional staff has the legal responsibility to disclose patient information without consent when a patient is likely to harm him/herself or others unless protective measures are taken, when there are reasonable suspicions of abuse or neglect of children, dependent adults or the elderly, when the patient lacks the capacity to care for him/herself and when there is a valid court order for the disclosure of patient files. However, these are rare situations. By signing a consent form, the patient gives us permission to communicate with the emergency contact designated if the staff believes you arc at risk. Any questions about this may be addressed with the behavioral health provider.

Counseling and therapy can have both risks and benefits The counseling process may include discussion of personal challenges and difficulties which can elicit uncomfortable feelings such as sadncss, anger and frustration. On the other hand, counseling has been shown to have many positive benefits. It can often lead to improved social relationships, better work performance, solutions to specific problems and reductions in feelings of distress. However, there is no assurance of thesc benefits.

I agree and understand the above policies related to my participation in behavioral health services.

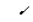

Patient Name (print)

Patient Signature

Guardian if patient under 18 years of age

Date 


\section{Appendix J}

\section{LIIA - Ifarpers Ferry Fumily viedictine Integrated Behavioral Health Services Privaly Practices}

'lhis notice describes haw medical incomation about yon riay bo used and disclosed ard how you wat get access to this inCormation. Please noview sarefully.

Our Juty to Salcguetd

Yoer Prolcel tod Llealih lnformation

lnformation about you past, present, or future health or condition, the provision of healthere to you, or payment for the trealthcare is considered "liotected llealth Information" ("PlL"). We are required to protect your PH] and to bive you this Notice about our privacy practices that explains how, when, and why we may use ur disclose your J'HT. Fxcept ir very specific situations, we will only relcase the miniram necessary information to carry out the request.

We arc rcquired to follow the priwacy practices described in this Notice, though we reserve the right to change olfr privacy practies and the ternes of this Notice at any time. You roay icquest a copy of the new notje from your Lherapisl or office staff.

How We May Lse and Relcasc

your Protected Health Infomation

We use and release information about yul for many reasons. We have a limited right to use andiot teledsi information about zour for purposes af Lealment, payment, or bealtheare operations. Far ues beyond that, we must have you motten permiksion unless the lay peromits or requires us to miks the use or disclosure rithout you pomission. II we have to give out information ta another petson of bulgitess to perform a tunelion on aur bohalf, then we have to make sure that they will protect you information the same way we are required to protect you informatiol, For inslanes, if you have Medicaid, we are requised to scrid infonmation aboul you to the West Vitginia Fureal of Behavioral Hedth and [lealth Facilities and American Psycl Systems yo thal Medicaid will pay for you servies. We bave co base a mittell agreenent wijth then to insure us thut they are going to protect the information we send them.

U!ses and Releases Relating to Treatment, Paymenl, ot Health Gare Operations

Here are sond oxatuples of how information about you is shared or atleaded:

For Treatment: We will share itlomation with doctors, nurses, and other healthoare persontel in our facilities that are jnvolvod in providite your healtheare. For example, information about you will be shared anong members of your tcalunent leam at this agency or for consultation purposes.

To Obtain Payment: Wo may uso'diselose information abont you in ardes to bill and colloel poyment far your healtheare scruices. lior eximple, we tuay release

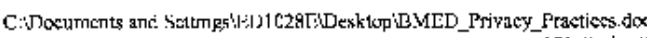

171 laylne Staet (Haljuri)

[301) $535-6743$ gh $63047575-6618$ fix inlomation about you to Merieaid, Medisare, or a private josurer so we can be paid for services deliwered to you.

For Hcaltheare Opurations: Tie may useiteleasc jnformaliun ubout you in the coursc of operating our agency. lior example, we may uge information about you lo evaluate the quality of our scrvices or when we are audited.

Appointment Remitedery; Litless you provide us with different instructions, wie may send letliss or eall your home ubuit carceled or rescheduled appointments.

Lises und Releases of Tnfomation About You from Medical Healt] Reenrds Rot Rcquiring Consent or Autlonization

Thare are times when the laws allow 115 to release information about you without your consenc in the following ways:

When Required by J aw: The law requjes we jeport information about suspected abuse, neglect, or domestic violence, or relalimg lo suspected crimithal activity. If we rccejve a signed euwr order by a judge, we must release the information reques led in the order. Sometines we hase to release infomation to the Medical Examincr (Coroner) if there's an inwestigation of a deatl]. Wc must also release information to authorities that monitor us in carrying out these privacy requirements.

lor Public liealth Activities. we may releasc ittontion when we are required to collcct joformation about disease or injury to the public health authonily

For Healch Oversight Actiwities: We my release irfurmation to state of federal agencies that come in periodically to cluck the way we provide out services and kęep out recatd.

Lo Avert Threat to Health or Safety: In onder to dwoid a serious threat to health or saficty, we may relcuse information as gecessary to law criorecment or uthor persons who can reasonably ptcyent or lessen the threat of ha्ञाm,

lior Specific Govennment Functions: wit ma release information of military personnel and veterene in etrtain situations, to correctional facilities in cerlairi situatiots, to government benefit programs of ating to cligibility and entolment, and for mational security reasons, such as protection af the President

Lses and Disclosures or PIII from Alcohol and Other Drue Records Nol Retuuiring Consent of Authorization: The law provides we may esseirelease information from alcoliol and other dnug records without consent or authorization in the following citeumstatece:

When kequired by Jaw: The law requires we report information about suppected abuse, neglect or domestic yiolence, or relating to suspected crimital activity. If we 


\section{IЛFA - Har pers Ferry Family Medicine lntcgrated Behavioral Health Services Privacy Practices}

reeive a signed court order by a judge, we must release the inlormationt requested in the ordcr. Sometimes we have wo relcuse information to the Wcdical tixanither (Coroncr) if there's an investigation of a deach we must. also release information to authoritics that minitor us in catrying out these privacy requirements.

L'o Awert Threat to Health or Safely: fri order to avoid a serious threat to bealth or sallety, we may release informution as necessary to law enforecment or ober persons who carr reasonably prewent or lesscr Llue threat of hasm,

Uses and Relcascs Roquiring You to Make an Opporturity to object: ln the following situations wo may diselose a limited amount of information if we intorm you about the disclosure in advance and you do not object as long as the disclosure is not otherwise prohibited by law.

To Familics, Fricands, or Others Involved in You Carc: Wo may share with these people information dircelly rx:lated to their involwement in your cate, or paytrett for your care. WF. may also share information with these people to rotify them aboul your location, geteral condition, or death.

Your Righls Regarditg Your Protected Health Jufontation: You have the following rights relatcd to the protceliun of your health information

To Request Restictions on Lsco/keleases: You have the rigltt to ask that wo limit bow we use or release information about you we will consider your request, but are not legally bound to agree to the restriction. To the extcont we do derce to any restrictions on our useitreleass of your information we will put the agreement in writing and abido by it except in emergency situations. Wo cannol agree to limit uses/releases required by law.

'To Choose Ilow We Contact You: You have he right to ask we send you information at an allenalive address or by allemative means. We must agrce to your request as long as it is reasonsbly easy for us to do so.

To Tuspect and RequesL a Cupy of Your Protecter Health Information: You have the right to see your protected health infortration unless your treatment team feels it is not in your best inleress to see it. We will respond to your written request within 30 days. If we deny your access, we will give you written reasons for the denial and explain any right to have the denial rcviswed. If you want copies of yout information, you wi]l be charged a copying Jee as allowed by state law You have the right to choose what partions of your information you want eopied and to be infortacd of the cost of copying.

To Request Amendment of Yout PIU; if you beljeve that there is a mistake on missing infomation in ous record of your information, you may request, in writing, wo sorred

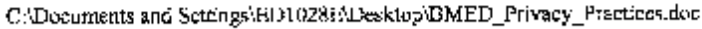

171 Tyylor Stretel (Dolivas)

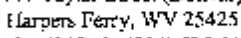

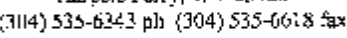

or add to the record. We will respond within 60 days of recciving your request. We may deny the request if we detcrmine thal the information is (1) conced and corniplete (2) not crcaled by us andior tot part of our records, or (3) not permilted to be disclosed. ANy denisil will state the reasons for denial and explain your rights to have the request and denial, along with any slatement in response that you providc, addad to your record. If we approye the request for amendment we will change the information and inform you, attd tell others that nect w now about the change in you informatiott

To Find Out What Disclosures llave Been Made: You have a right to get a list of when, to whom, or for what propose, and what content of your recerd has becr released other than instances of disclosure for traturent, payment, and operatiuns, to you, your family, or any release made with your authonization. The list also will not include any disclosures made for national sceurily puporses, to law enforcement officials or comretianal facililies, or disclosures made before $\lambda$ pril 2003. We will respond to your written request for uuch a list within 60 days of receiving it. Your request can relate to disclosures going as lar back as six years. There will be no charge for up to onc such list each year. There may be a cliarge for more frequent roques13.

To Rccive l'his Notice: You have the right to receive a paper copy of this Notice andor an electronic copy by email upon reculest.

How to Complain Aboul Our Privacy Practices: Tf you think we may have violated your privacy riglts, or you disagecc with a decision we made about access to your record, you may file a cormlaint with the Secretary of the US Department of Heulth and lluman Services at 200 Independeree $A$ veruc, SWW, Washington, DC 20201 or call 1-877-696-6775. We will take no retaliatory action against you if you make such eonglaints.

I understand these rights as I have read them and/or they have becu cxplained to me. I undersiand I will bc given a written copy of the Notice of Privacy Practices at my reguest.

Conwmer/Guardian Signame

Print Nane

Dafe 


\section{Appendix K}

\section{UHA - Harpers Ferry Famlly Medicioc \\ Integrated Bchavioral Hetalth Services \\ INFORMED CONSENT TO TREATMENT WITII MEDICATION}

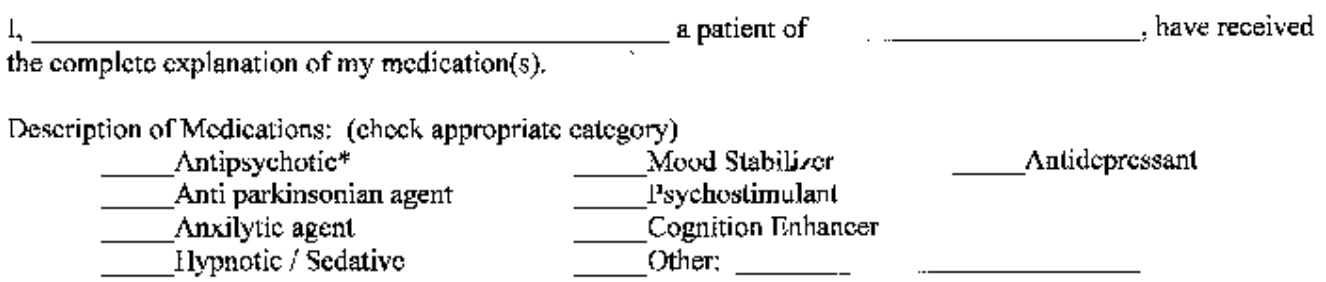

My provider has discussed with me the nature of my psychiatric / behavioral problems for which medication has been preseribed. My provider has discussed with me the reasons why medication may be helplul, ftoluding the likelihood of my psychiatric / behavioral problems improving or not improwing with medication, and I have been informed of the conscquences of my rofusing medication. If effective treatment alternalives are available, my provider has discussed them with me. I bave been informed of the potential side cffects and risks reasonable to be expected from this medication. I have decided to accept medication as preseribed for the treatment of my psychiatric / behavioral problems at this time. I understand that I may change my decision to accept medication and that if I change my decision l will contact my provider. It is important to report to my provider the emergence of any side effects.

*The symptoms and rishs of Tard twe Dyshinesia and NEwroleptic Malignant Syndrome hove been explained to me

\begin{tabular}{|c|c|}
\hline Patient & Date \\
\hline Representative & Jate \\
\hline Relationship to Patient & \\
\hline l'erson Giving Explanation & Position \\
\hline Provider & Date \\
\hline
\end{tabular}

If this consent is for treatment of a minor or for a patient that is ungble to give consent, the following information must be provided:

a) Vame of one or both parents, if knowit:

b) Name of mangging conservator or guardian or person, if appointed:

c) Date on which treatmonl is to begin:

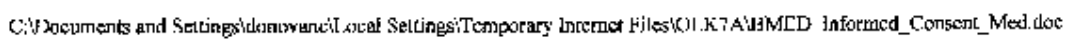

171 เimls Streel (Eoljyar)

(304) 535-6:43 ph (304) 535-6018 fis 


\section{Appendix L}

\section{UHA - Harpers Ferry Family Modicine \\ Integrated Bchavioral Heglth Services \\ INYORMED CONSENT FOR TIIE REJ,FASE OF CONFIDEN'CIAL INFORMATION,}

$\mathrm{I}$, , dale of birth authorize UIIA - Integrated

Behavioral Health Scrvices, to exchange information relaled to my trealment with

The purpose of this relcasc is

I understand that this authorization may be revoked and updated by me at any time except for information that has already boen rcleased under this or previous ałthorizations. I horeby release UHA - Integrated Rehavioral Health Services from all liability that may arise from the relcase of the information requested. I understand that my recurds are protected under the federal regulations governing. Confidentiality of Alcohol and Drug Abuse, Patient Records, 42 CFT Part 2, and cannot be disclosed without my written consent unless otherwise provided for in the regulations. I also understand that I may rewoke this consent at any time except to the extent that the action has becn taken in reliance on it. 


\title{
Appendix M
}

\begin{abstract}
UШA - Harpers Ferry Family Medicine Integrated Bchavioral Health Scrvices PATIFNT INTAKE FORM Self Information Sheet
\end{abstract}

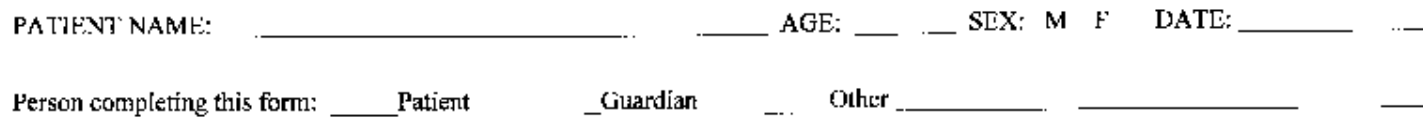

: Depression

$\sqcup$ Does not feel joy

П Hopelessness

ᄂ Worthlessness

$\square$ linergy level

ㄷ. Concentration

ᄃ Sleep.

Weight

- Memory problems

Appetite

Irritability

- Sexual issues

- Suicidal thoughts

$\sqcup$ Thoughts of harming olhers

Provider Notes:

_.. Other

Do you have any problems with alcohol or other drugs?

Yes 11 No

If yes:

Do you need to cut down on alcohol/drug use?

Y Yes $\Gamma$ Ko

Do you feel angry when someone talks about your alcoholidng use?

$\checkmark$ Yes | No

Do you feel guilty aboul your alcohol/drug use?

$\sqsupset$ Yes $L$ No

Do you need alcoholdrugs to gel you going in the moming?

$\neg \mathrm{Yes}=\mathrm{No}$

Does stopping alcohol/drug cause:

Palpitations, flushed skin, sweating

$\square$ Yes . No

Increased hand tremors

$\sqcap Y \mathrm{es} \sqsupset \mathrm{No}_{0}$

Insomnia

Nausedromiting

$\sqcup$ Yes . I No

Hallucinations

$[$ Yes $\quad[\mathrm{No}$

Y Yes $\square$ No

Agitation

- Yes $\square$ No

Anxiety

- Yes $\Gamma$ No

Sejrares

Z. Yes L: No

Social impainment

I Yes $\sqsubset$ No

Moncy spent on alcoholidrug per day Lcgal problems due to alcohol/drug

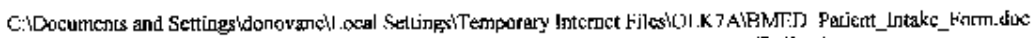

171 laylor Strect (Holliver)

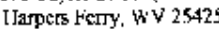

(904) 535.6343 ph (3) 535-66 Is tax 
Financial problems duc to alcohol/drug

Provider Notes:

Have you cver had any of these symptoms over a period of time?

\begin{tabular}{|c|c|}
\hline- Yes & $\sqsupset N_{0}$ \\
\hline $\operatorname{Ycs}$ & \rceil No \\
\hline 7 Yes & $\square \mathrm{No}$ \\
\hline し Yes & $1 \mid \mathrm{No}$ \\
\hline$\square$ Yes & $\sqsubset \mathrm{No}$ \\
\hline$\square$ Yes & $\sqsubset \mathrm{No}$ \\
\hline$\square \mathrm{Ycs}$ & $\subsetneq$ No \\
\hline ! : Yes & No \\
\hline Yes & $\neg V_{0}$ \\
\hline - Yes & ل \\
\hline
\end{tabular}

Racing thoughts

Excessive spending

Sell-importance

Impulsive behaviors

Cannot slocp.

Mood swings

Talks too tast

Exccssive energy

Increased sexual drive

Dangerous behaviors

Mild devation of mood

Positive thinking for few days

Increased energy lot fow days

Provider Noles:

-

Have you been constantly anxious/worried with these symptoms for al least 6 months?

\begin{tabular}{|c|c|c|}
\hline ¿ Yes & $-N_{0}$ & Cannol control worry \\
\hline Yes & : No & Incrcased irritability \\
\hline Yes & I No & Musele tension \\
\hline$-\mathrm{Ycs}$ & $\square N_{0}$ & Sleep disturbanec \\
\hline i: Yes & $11 \times 0$ & Decreased concentration \\
\hline [ Yes & $\sqcup \mathrm{No}$ & Incrcased fatigue \\
\hline$\square \mathrm{Yes}$ & $\ulcorner\mathrm{No}$ & Restlessness or focling kcyod up, on edge \\
\hline Prowide & Notes: & 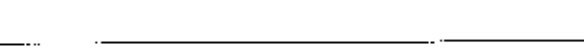 \\
\hline
\end{tabular}

Ilave you had any of these symptoms over a pertod of time?

- Yos J No Panic allack

- Yes J No Palpilations

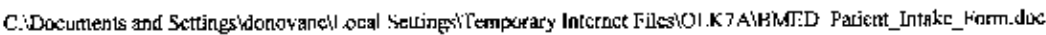

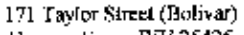

(704) 535-634) ph (904) 533.6518 far 
PATIENT NAME:

- Yos $\square$ No

Sweating

1 ) Yes $\square \mathrm{Na}$

$\sqcup$ Yes I. No

Trembling

1) Yes $\Gamma$ No

IYes - No

Z Yos 」No

- Yes $\neg \mathrm{No}$

- Yes $\sqsupset$ No

\lrcorner Yes II No

Provider Notes:

Shaking

Shortness of brcath

Chest pain

Nausca

Fear of dying

Fcar of losing control

Unusual serssations (e.g. tingling in arms $/ \mathrm{cgs}$ )

\begin{tabular}{lll}
\hline & & \\
\hline 1! Yes & No & Excessive fear or anxiety when among strangers \\
- Yes & . No & Avoid pcople/places because of anxiety \\
Provider Notes:
\end{tabular}

$\square$ Yes $\sqsubset$ No $\quad$ Persistent thoughts, impulses, images which are intrusive/inappropriatc and cause anxiety

$\Gamma$ Yes - No Recognize that thoughts are product ol own mind

Yes : No Repetitive or ritualistic bchavior

Provider Notes:

Have you witnessed or undergone a life-threatening event?

If yes, plcase describe the event:

Provider Noles

Intense fear, helplessness, horror about the incident

Reliving experience ( 7 ashbacks)

Distressing recollections or dreams

A voidance of stimuli that are associated with the trauma

Fear that something bad is going to happer (hyper vigilance)

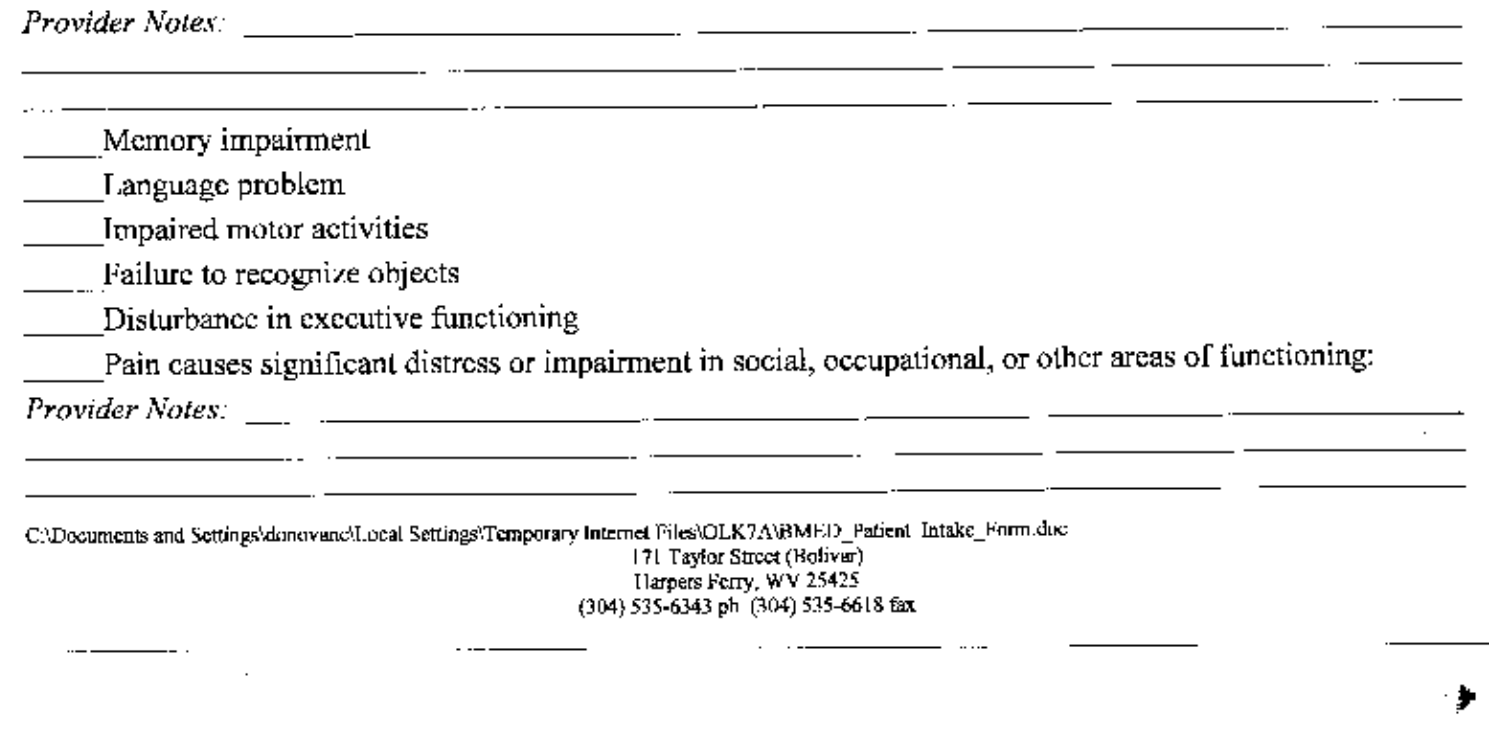


Intcnse for of weight gain

Refusal to maintain weight

Absence of menstruation

Disiorted body image

Binge ealing

Lack or conlrol over eating

Lating all the lime

Self-indued vomiting

..... ... Use laxatives, diutelics, enemas

Provider Noles:

Cannot go to sleep (or stay aslecp) for at least 1 month

Provider Notes:

liailure to resigt aggessive impulses that result in scrious assaultive acts or destruction of property

Degree of aggression greater than any psychosocial stresses

Provider Notes:

Delusional (unusual belicfs)

I Ialucinations (heating voices/seeing things)

Speech that does not make sense

Catatonic behaviors (mute all the time)

Stays in one place all the time

Unable to work or perform nomal social functions

Duration

Provider Moter:

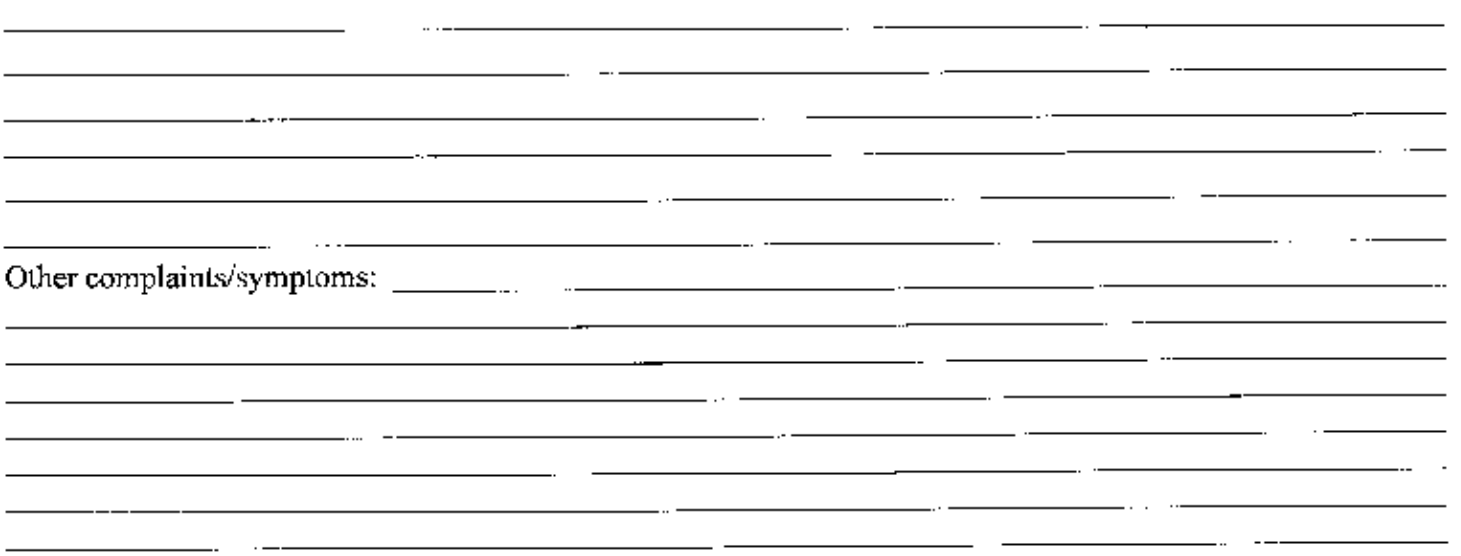

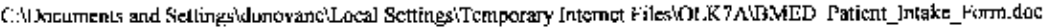

171 'layler Streer (Eolivar)

Harper: Ferry, Wr 25425

(50) 535-6343 of (304) 535-6618 fax 


\title{
Appendix $\mathrm{N}$
}

\author{
UHA - Harpers Ferry Family Mcdicine \\ Integrated Behavioral Health Scrvices \\ TELFPHONE APPOINTMENT REMINDFR CONSENT
}

$I_{2}$ Paticnt Name (print) give Provider Name (print) and members of his/her stalT working at the location indicated above my permission to call me ptior to an appointment to remind me of the appointment date and time.

I would prefer to be called at (check all that apply):

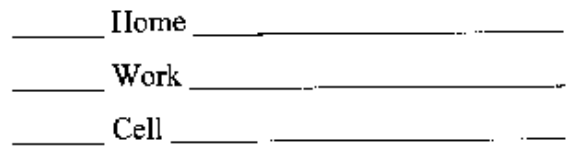

Yos, this office may leave (check all that apply):

Voicemail at my Home

Messages with people at my Home
_._ Voicemail at my Work

Voicemail on my Cell Messages with people at my Work

I understand that I may withdraw this consent at any time. either verbally ar in writing except to the extent that action has been taken on teliance on it. This consent wi]l last while I an beitg treated by the physician specifled above unless T withdraw my consent during treatment. This consent wil] expire 365 days after I complete my treatrnent, usless the physician apecified above is otherwise notified by me.

Patient Signature 


\section{Appendix $\mathrm{O}$}

\section{Integrated Behavioral Health Clinician (Therapist) Job Description}

\section{SLMMARY:}

The Integated Behavioral Hcalth Clinician, as part of the primary care Ircatment tearn, identifies triages and manages paticnts with behtwioral health problems within the primary care setting. In addilion, the Integrated Behavioral Health Clinjcian will provide skill training through psycho-education and paticnt education strategies and will dewelop specific behavioral change plans for patients and behavioral health protocols for target populations.

\section{ESSEYTLAL DUTIES ANT RESPONSIBILITIES:}

- Provide brief mental beallh assessmont, troatment, and/or referral to specialty mental health scrvices.

- Assess patients noeds as defined by specificd physician consultation.

- Livaluates current behavioral and psychosocial symptoms and provides foedback to the PCP and team.

- Ptovides paticnt education regarding symptoms and diagnosis.

- Tovvides interventions that are culturally sensitive, evidence - based, simple and applies palient strongths.

- Consults with the PCP team on various bchavioral heallh and psychosocial issues.

- Triages paticnts to spccialty mental health as necded.

- Documents patient visil, paticnt carc and treatrment decisions in the medical record. Fhe relerring provider will have access to such medical record.

\section{QUALIFICATIONS:}

- Good working knowledge of behavioral heallh and evidence-based treatments lot mental health conditions

- Ability to make expeditious and aceurate clinical assessments of mental and behavioral conditions

- High level or comfort working with primary care providers

- Ability to work through brief paticnt contacts

- Ability to work effectively in a team interfacing with patients, primary care prowiders, mental health providers and with administrative and support staff

- Ability to provide short tcm solution focused interventions and psychoeducation 


\section{Pg.2}

EDUCATION and/or EXPERIENCE:

- Masters in Social Work or

- PhD/ PsyD in Psychology or

- Masters prepared Advanced Praclice Psychiatric Nutse

\section{LICENSF and CERTIFICAIION:}

- Currenl WV liecnse as an T.CSW or

- Current WV license as a psychologist or

- Current WV RN licensure, MSN in nursing, and ANCC certification as an advanced practice psychiatric nurse 
Appendix $\mathrm{P}$

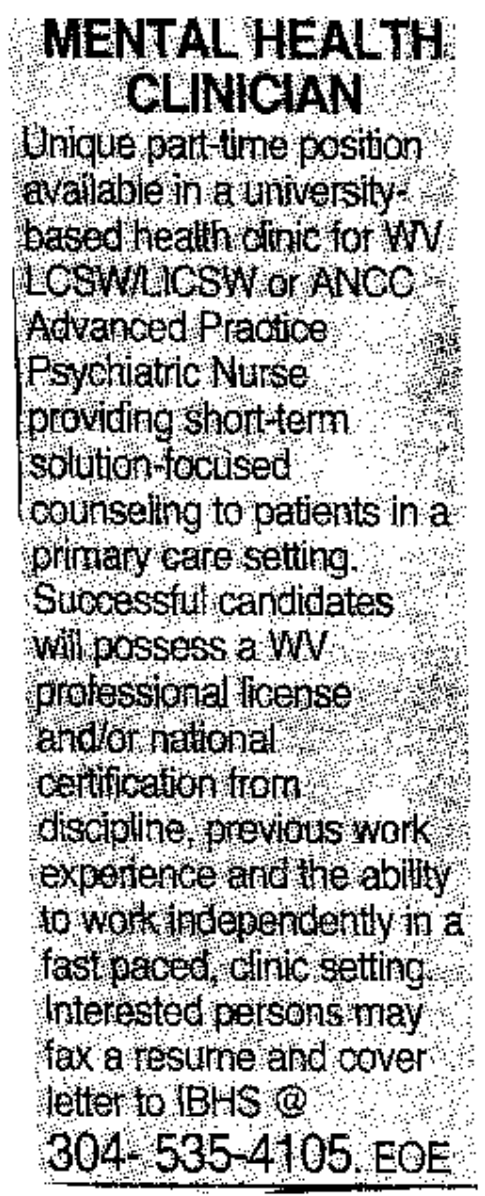




\section{Appendix Q}

\section{Education:}

Masters in Social Work: West Vinginia Unipextily, June 2003

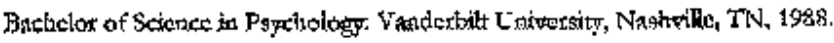

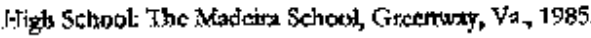

\section{Emplomicht Hintors:}

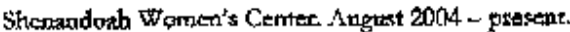

Wartingbutg. WW

Titter Counselot/socind Wotkes.

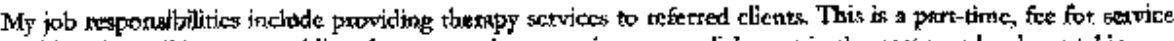

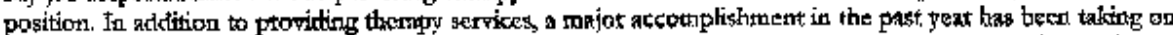

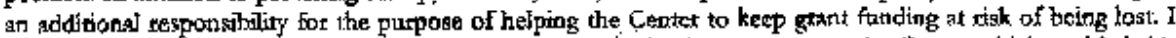

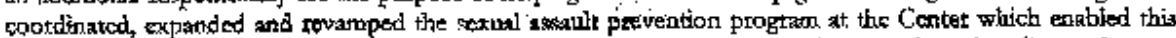

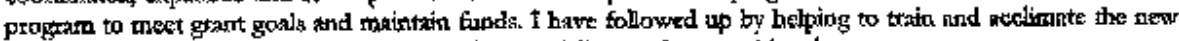
indiridual who has been hited as the prewcrtion ppectalitst no take over this role

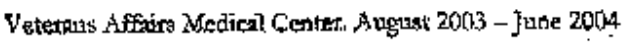

Mattirsburg, Wy

Tirle: Social Warker, Center for Addiction Trentraent (CAT' of at the VAislC.

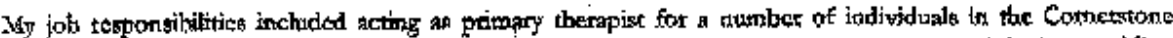
Work Recovery tritk of the CAT 5 prografn, ti welkttion to being a thenpist, I was reapansible for providing woeptional assistrnes to parients in the progtam. I developed job contacts and tegularly exploted job

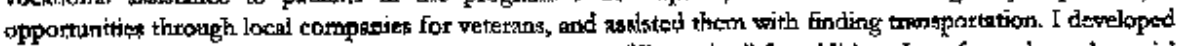

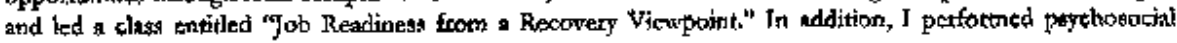
nasessments on math of the newly adtoritted patienth.

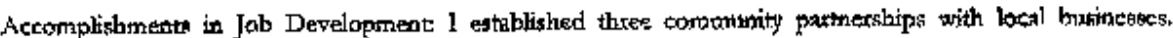

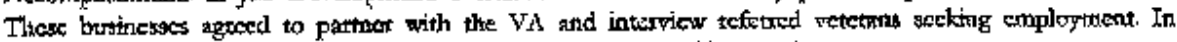
addition, I developed a tandatediaed prateduri for individuala seeking entployment.

VAMC, Augist 2002 - MAY, 2003

Mattiasbutg, WV

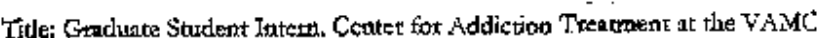

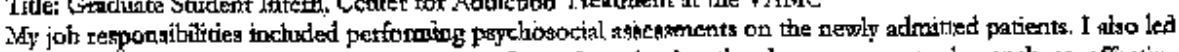

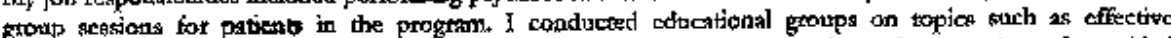

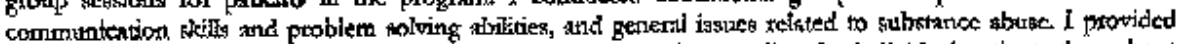

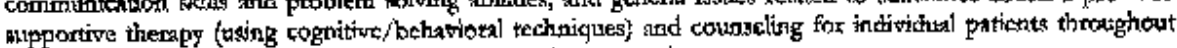

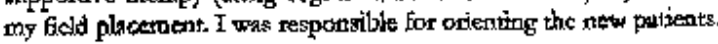

Fixt Ridge Health STstenx Septentber 1.9p - July 1994.

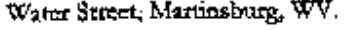




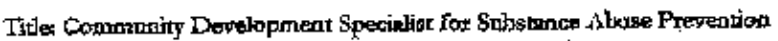

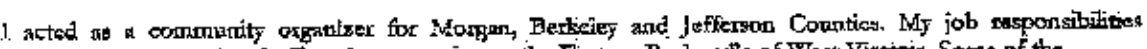

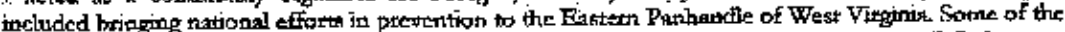

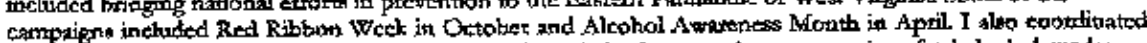

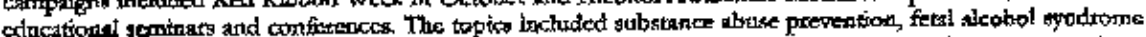

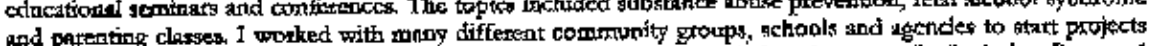

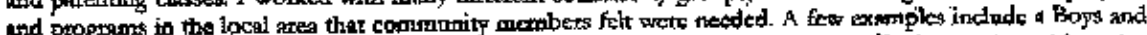

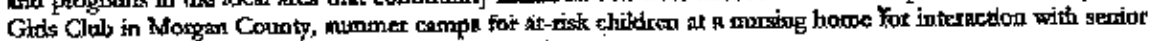

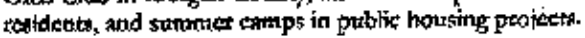

Dongthin Futriture and Tarting 1989

Soho, NGw Yot NY.

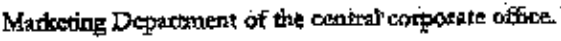

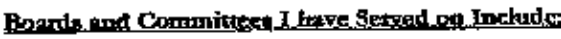

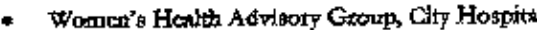

- Choiperson for the Fiealth and Huan Services Task force for Foots

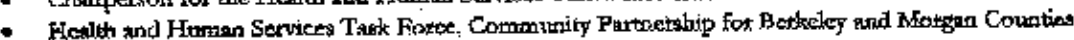

- Pexiratil lssues Tapk Foner Focts

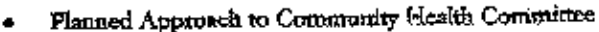

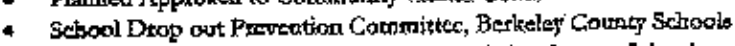

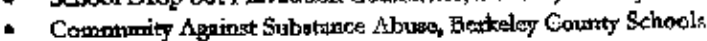

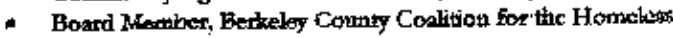

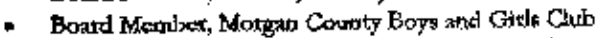

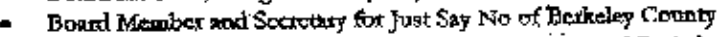

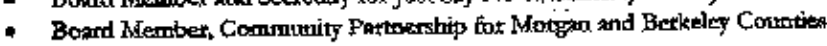

- Core Tenm Jefferaon County schopols

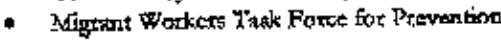

\section{Awardor}

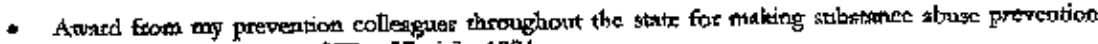
cfforts grow in the state of Weat Wiginia, 1994

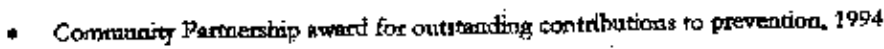

- Awrot from the FOCUS conition an sibstndes nbuge for ptovention, 1994

Refereden awalibile upob nequest 


\title{
Appendix R
}

\author{
Social Worker Introduction
}

My name is $\quad$ and I an a Social Worker. I am working at Harpers Ferry Family Medicine and Jefferson Maternity Center for three months as part of a project. I will be working under the supervision of your physician. The project permits me to provide counseling and education to patients who have expressed concerns about situations in their lives whith need to be addressed. Your provider will refer you to see me to discuss these situations. After an interview with the nurse practitioner, I will meet with you for four to six sessions to help you learn about your illness and learn new ways of coping. I do not provite long term psychothetapy sessions. Instead, it is my job to help yoli and your provider better manage the stress in your life and make lifestyle changes.

Information discussed in the sesstons is confidential with a few exopptions. One exception is if you reveal the intent to hurt yourself or someone elsp. In addition, I ath obligated to report incidences of child abuse.

Please let me know if you have questions. I look forward to working with you. 


\section{Appendix S}

\section{REFERRAL FORM}

Name of referral
Birth date

Birth date

Resson for teferral:

Psychiatric history:

\section{Current medical problenns:}

Current medications:

Individual minaking referral

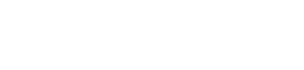

Hagen 